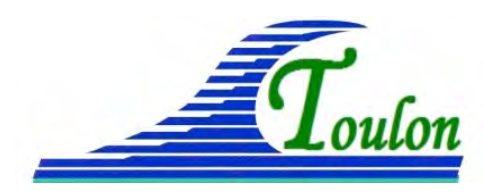

XIV èmes Journées Nationales Génie Côtier - Génie Civil Toulon, 29 juin au $1^{\text {er }}$ juillet 2016

DOI:10.5150/jngcgc.2016.081 C Editions Paralia CFL disponible en ligne - http://www.paralia.fr - available online

\title{
Nouvelle Route du Littoral à la Réunion - Viaduc de 5400 m : Conception et méthodes de réalisation d'un ouvrage en mer exceptionnel
}

\author{
- LECTURE SPECIALE -
}

\section{Jean-Michel CHARPENTIER ${ }^{1}$, Romain LEONARD ${ }^{2}$, David BOREL $^{3}$, Guillaume DANAN ${ }^{4}$}

1. Vinci Construction Grands Projets, Directeur Technique, 97420 Le Port, France. jean-michel.charpentier@vinci-construction.com

2. Demathieu Bard Construction, Directeur Technique Adjoint, 97420 Le Port, France.

3. Bouygues Travaux Publics, Responsable des Méthodes, 97420 Le Port, France.

4. Egis, Chef de Projet Viaduc, 97420 Le Port, France.

\section{Résumé :}

Le chantier de la Nouvelle Route du Littoral (NRL) à la Réunion comporte en ouvrage d'art principal un viaduc en mer de $5400 \mathrm{~m}$. Les principales caractéristiques techniques de cet ouvrage exceptionnel sont présentées, ainsi que le contexte maritime dans lequel il a été conçu et réalisé. L’article détaille ensuite les diverses solutions mises en œuvre, tant en conception qu'en méthodes d'exécution, pour permettre la réalisation de ce projet et la maîtrise des conditions de son exécution en mer.

Mots-clés : Génie côtier, Travaux maritimes, Protection contre l'érosion, Fondations sous-marines, Travaux offshore.

\section{Préambule}

La Nouvelle Route du Littoral (NRL) permettra aux habitants de l'île de La Réunion, dans l'océan Indien, de relier en toute sécurité Saint-Denis, la capitale à l'est, et son port de commerce situé une vingtaine de kilomètres plus à l'ouest. Elle remplacera l'actuelle route de la corniche (RN1), à deux fois deux voies, située au pied d'une falaise. 


\section{Lecture spéciale}

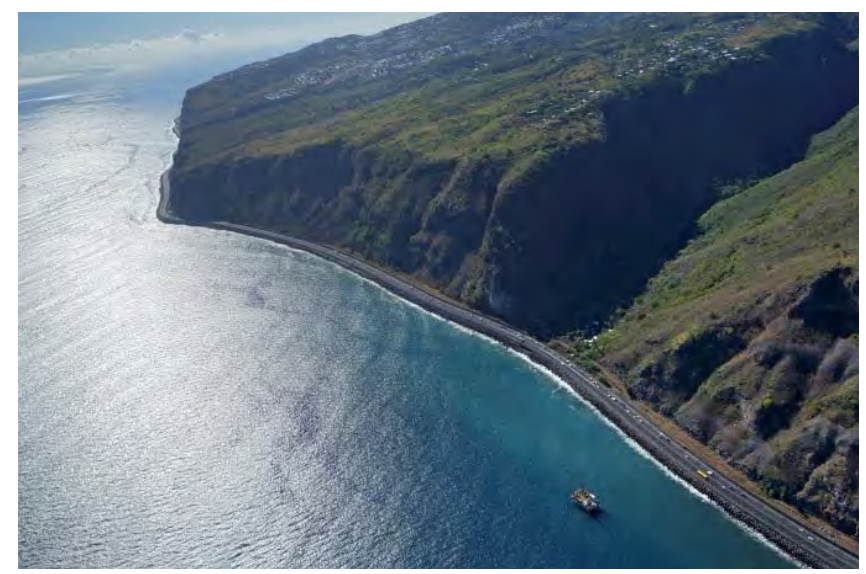

Figure 1. La route actuelle en pied de falaise.

Cette route dangereuse fait courir deux types de risques à ses usagers :

- côté mer, exposition aux franchissements en cas de forte houle, ce qui arrive fréquemment du fait de l'absence de plateau continental ;

- côté montagne, exposition aux chutes de pierres et aux éboulements de falaise, malgré la présence de filets de protection et d'un système préventif de basculement/fermeture de chaussée déclenché en fonction de niveaux pluviométriques.

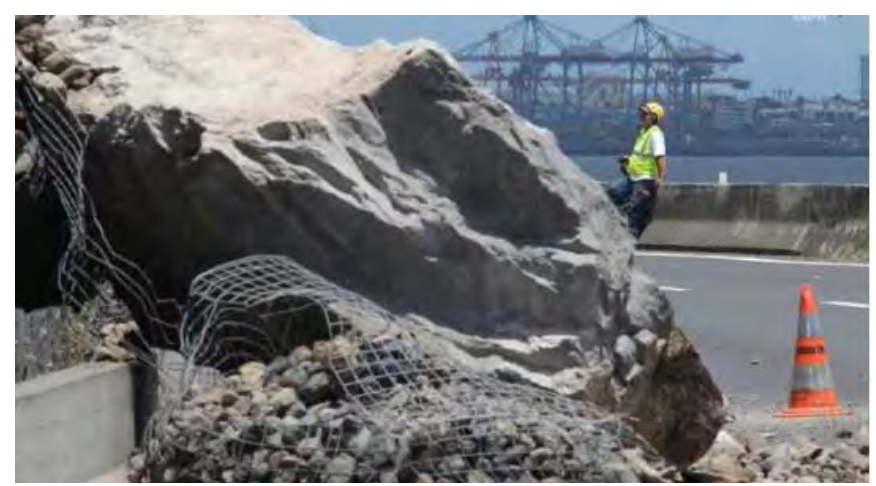

Figure 2. Chute de 15 tonnes de blocs rocheux le 03/03/2016.

Ainsi, deux mois par an en moyenne, pour protéger les usagers, les autorités doivent fermer une ou deux voies de circulation, provoquant de vastes embouteillages.

Le projet de la nouvelle route du littoral (NRL) s'étend sur une longueur de $12.5 \mathrm{~km}$ entre l'entrée Ouest de Saint-Denis et La Possession. Il est presque entièrement situé en mer. La future route, parallèle à la côte, permettra de s'affranchir des chutes de pierres et éboulements de falaise, mais aussi de la houle, puisqu'elle se situera entre 20 et $30 \mathrm{~m}$ au-dessus du niveau de la mer. La chaussée de la NRL permettra une exploitation à 2 fois 2 voies + une voie TCSP dans un premier temps tout en assurant le passage de 


\section{XIV ${ }^{\text {èmes }}$ Journées Nationales Génie Côtier - Génie Civil \\ Toulon, 29 juin au $1^{\text {er }}$ juillet 2016}

circulations douces (piétonnes et cyclistes). A terme un transport en commun en site propre pourra être installé.

Les ouvrages majeurs de cette liaison comprennent :

- un viaduc de 5,4 km - il sera le plus long viaduc de France que ce soit terrestre ou maritime.

- le viaduc de la Grande Chaloupe, d'une longueur de 240 m ;

- une série de digues d'une longueur totale de 6,7 km ;

- deux échangeurs dénivelés (Grande Chaloupe et La Possession)

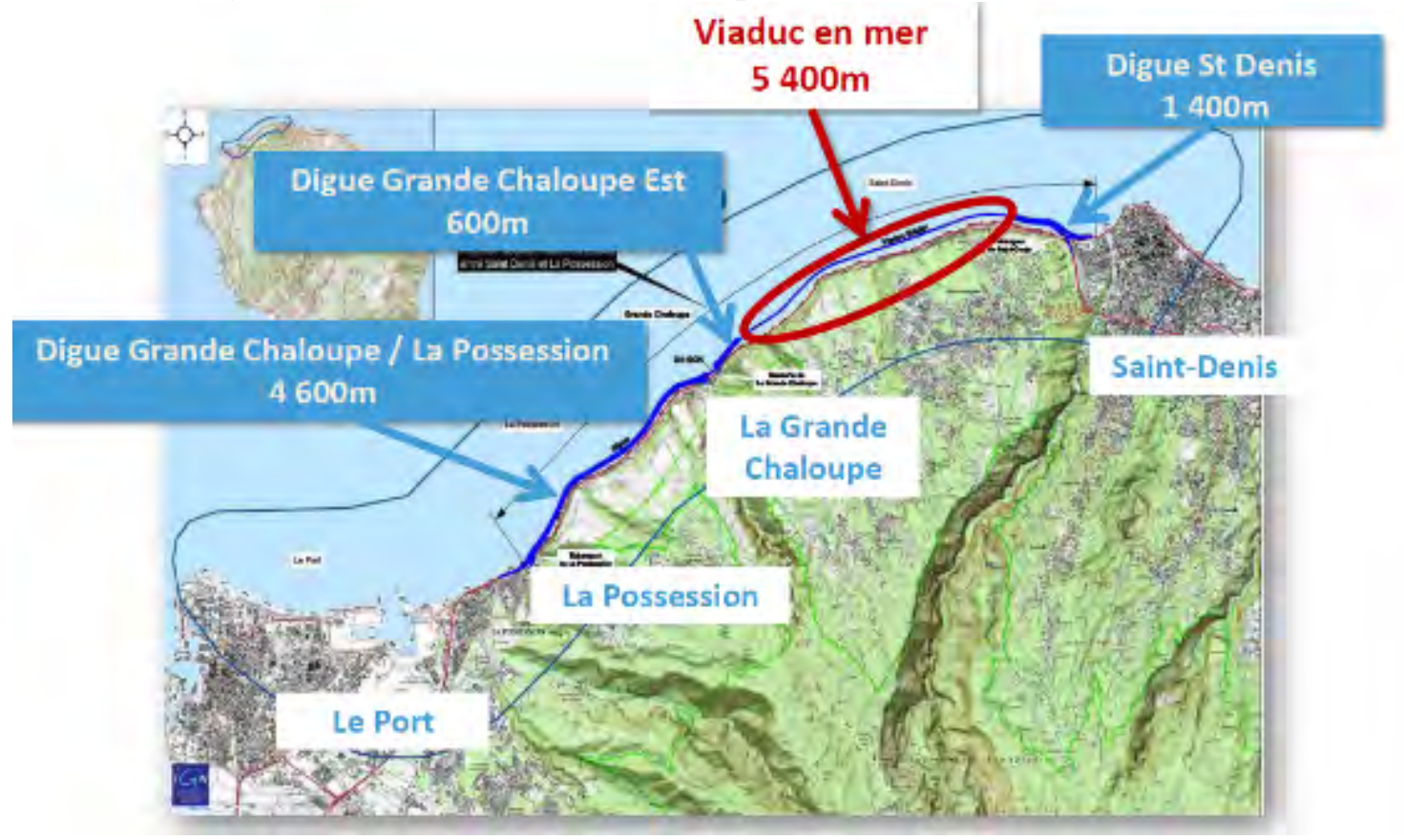

Figure 3. Plan d'ensemble de la Nouvelle Route du Littoral.

Cet article vise à présenter l'ouvrage d'art principal - viaduc en mer de $5400 \mathrm{~m}$ - et les solutions imaginées tant en conception qu'en méthodes d'exécution pour la réalisation de cet ouvrage en mer exceptionnel.

Le maître d'ouvrage de la NRL est la Région Réunion. Le maître d'œuvre est EGIS.

La construction du viaduc (marché $\mathrm{n}^{\circ} 3$ - MT3) a été confiée au groupement d'entreprises VINCI Construction Grands Projets (mandataire), Dodin Campenon Bernard, Bouygues Travaux Publics et Demathieu Bard Construction pour un montant de 715 millions d'euros TTC.

\section{Description du projet}

La partie viaduc de la NRL est située essentiellement en mer à l'écart de la falaise. Elle est conçue pour une durée de vie de 100 ans, notamment vis-à-vis de la contrainte maritime (houle cyclonique) et de la durabilité des bétons. Elle est également conçue 


\section{Lecture spéciale}

pour permettre l'intégration ultérieure (mode 2) d'un transport collectif en site propre (TCSP) routier ou ferroviaire (de type tramway).

L’ouvrage est soumis à des aléas météorologiques (la houle, les cyclones, les alizés), à des aléas sismiques (zone de sismicité faible) et aux chocs de bateaux.

Le viaduc est constitué de 7 tronçons indépendants reliés par des piles-culées. Chacun des 7 tronçons comprend 7 travées (6 fléaux identiques de 120,0 m et deux demi-travées de rive de 42,322 $\mathrm{m}$ ).

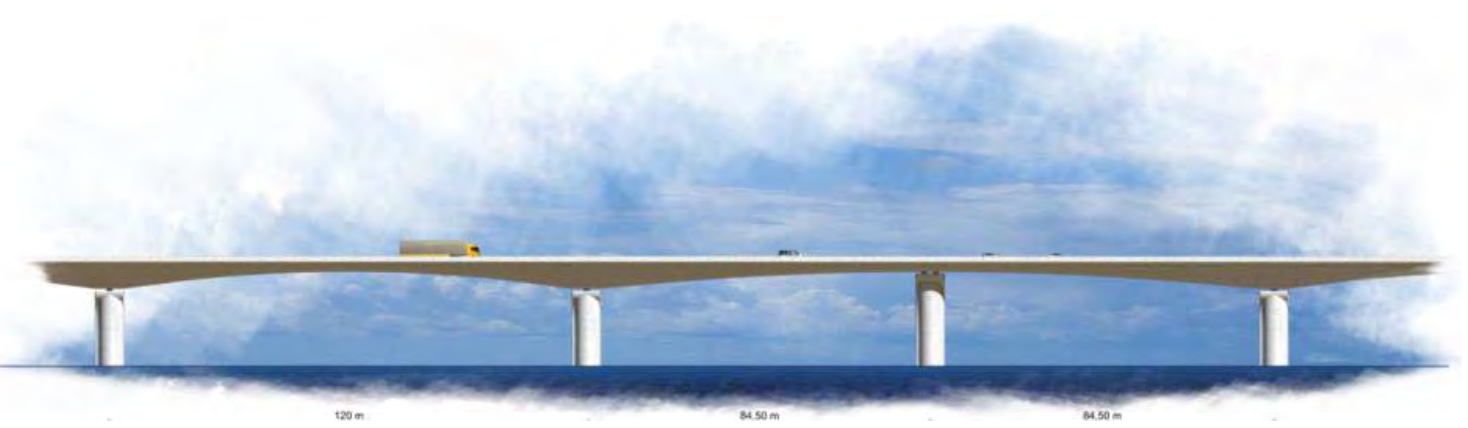

Figure 4. Elévation architecturale - travée courante et travées de rive.

Les tronçons ont une longueur de $771.285 \mathrm{~m}$ pour les tronçons de rive (1 et 7) et de 773.286 m pour les tronçons intermédiaires (2 à 6), entre axes d'appuis d'extrémité de tronçon.

Les appareils d'appui d'extrémité de deux tronçons adjacents étant distants de $4.0 \mathrm{~m}$, la longueur totale de l'ouvrage entre axe d'appareils d'appui d'extrémité est donc de $2 \times 769.285+5 \times 769.286+6 \times 4,000=5409.000 \mathrm{~m}$.

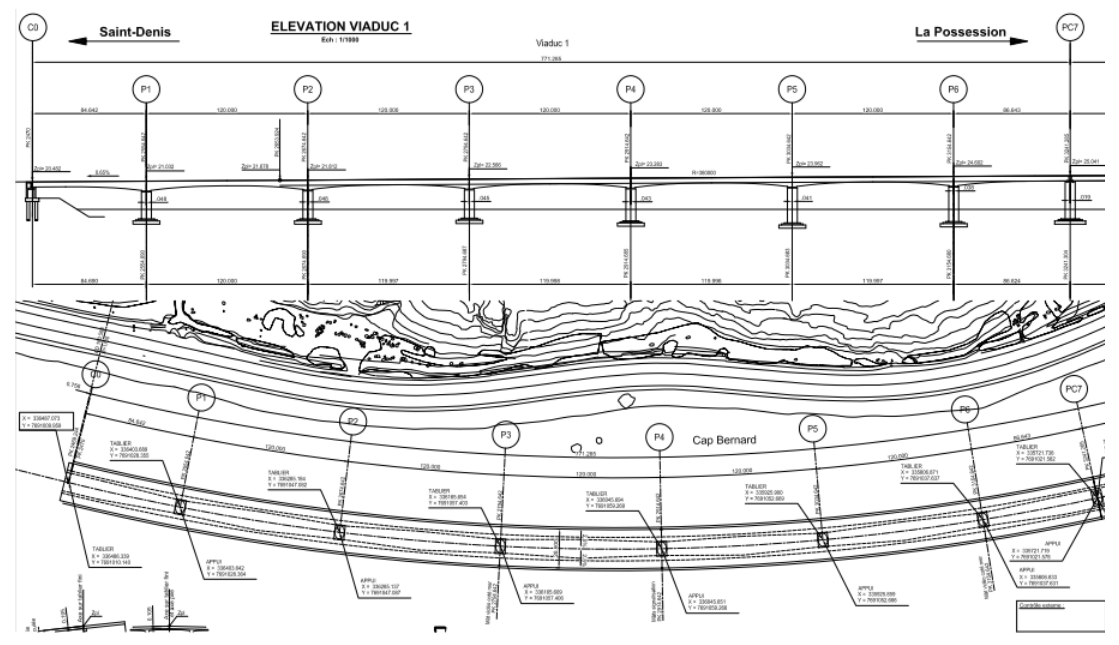

Figure 5 élévation et vue en plan du viaduc 1 (Est).

L'ouvrage est situé entre les PK 2+470 (axe d'appui C0 côté Saint Denis) et 7+879 (axe C49 côté La Possession). 


\section{XIV ${ }^{\text {èmes }}$ Journées Nationales Génie Côtier - Génie Civil \\ Toulon, 29 juin au $1^{\text {er }}$ juillet 2016}

Il présente un sommet au PK 5123.883 avec une altitude $\mathrm{z}=29.705 \mathrm{~m}$.

Le profil en long est défini sur l'axe du viaduc. La vue en plan est une succession de courbes dont la plus petite présente un rayon de courbure de $1500 \mathrm{~m}$. Ces faibles courbures permettent de conserver un profil transversal en toit centré sur l'axe de référence, correspondant à un dévers constant de $\pm 2.5 \%$ de part et d'autre de l'axe.

Le maître d'ouvrage a prévu un mode d'exploitation routier avec voie de bus dédiée à la mise en service, pouvant évoluer par la suite en intégrant notamment un TCSP ferroviaire selon deux scénarios différents, ce qui donne 3 profils enveloppes :

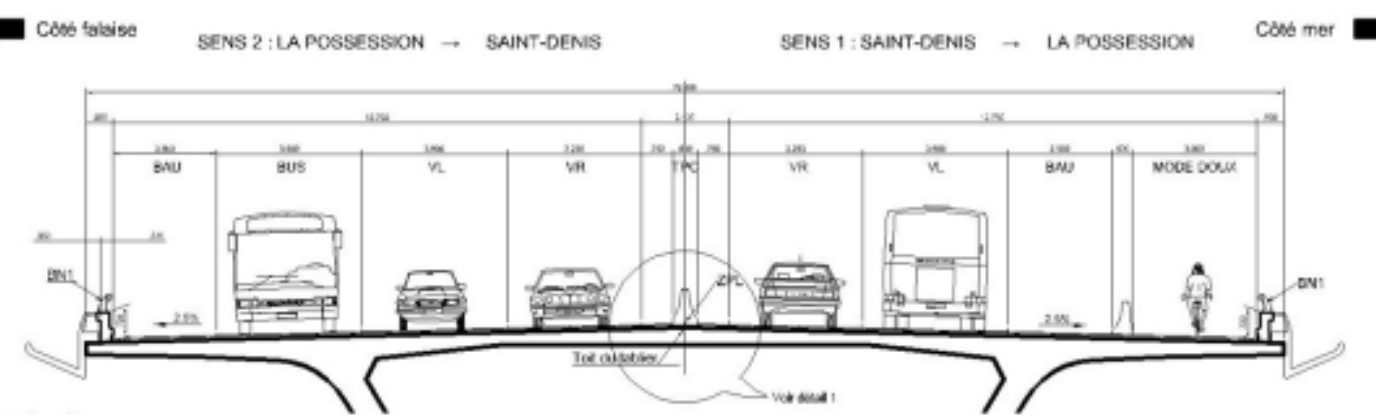

Figure 6. Mode 1 - coupe fonctionnelle à la mise en service - circulation routière $2 \times 2$ voies avec une voie bus dédiée côté falaise.

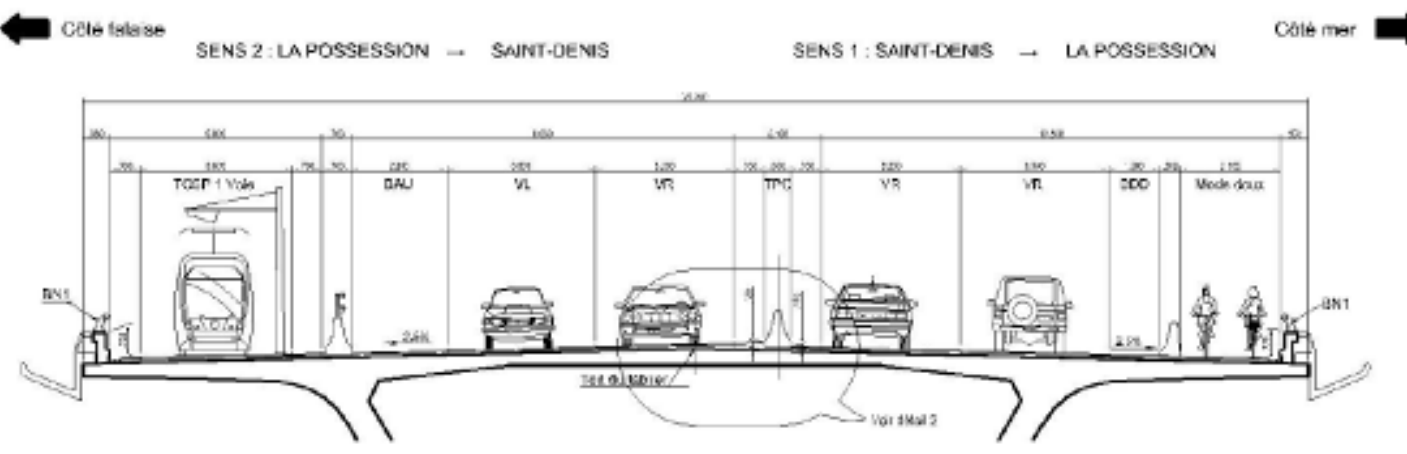

Figure 7. Mode 2a - Tramway en site propre en circulation alternée.

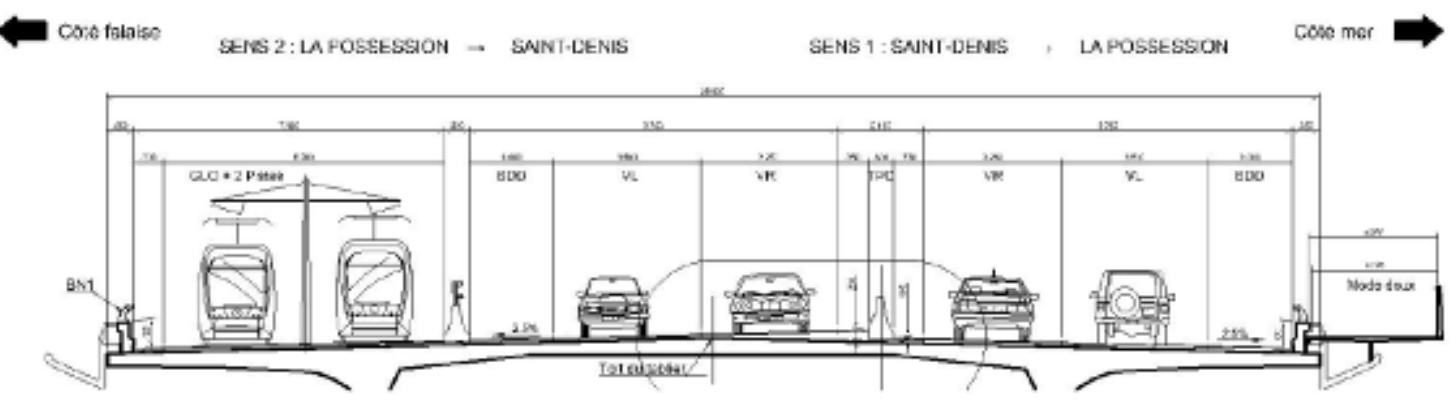

Figure 8. Mode 2b-Tramway en site propre 2 voies. 


\section{Lecture spéciale}

Le mode $2 \mathrm{~b}$ avec 2 voies TCSP Tramway correspondra à la phase finale de l'aménagement avec l'introduction latérale coté océan d'une passerelle restituant les modes doux.

\section{Contexte maritime}

Le viaduc de 5400m est situé en totalité sur un étroit plateau côtier formé par apport de matériaux (blocs et éboulis provenant de la falaise, sables d'origines diverses) sur un substratum de coulées basaltiques. L'ouvrage se situe à une distance variant entre 60 et $300 \mathrm{~m}$ du rivage, qui est entièrement artificiel (remblai et ouvrages de protection de l'actuelle RN1). Les pentes transversales (maximum 2,5\% au droit du viaduc) et les profondeurs (de 8 à $11 \mathrm{~m}$ ) du fond marin sont faibles.

\subsection{Conditions de houle}

L'ouvrage est entièrement situé sur le littoral Nord de la Réunion, soumis à des conditions de mer assez difficiles. On distingue (source BRGM) :

- Les houles d'alizés, qui sont les plus fréquentes, de secteur dominant Sud-Est. A proximité du rivage, ces houles sont à l'origine de deux dérives littorales, contournant l'île par l'Est et l'Ouest, et dont les courants convergent du côté opposé, entre la Pointe des Galets et l'embouchure de la Rivière des Galets. Ces houles d'alizés présentent une hauteur moyenne d'environ $2 \mathrm{~m}$ sur la côte au vent, amplitude plus marquée en saison fraîche (mai-octobre) et atténuée en saison chaude (novembreavril). Leur période est comprise entre 9 et 12 secondes.

- Les houles australes, qui proviennent de tempêtes formées à 3000 km au large, dans la zone tempérée de l'hémisphère Sud et atteignent les rivages réunionnais 15 à 25 jours par an. De plus grande longueur d'onde (période comprise entre 12 et 20 s), de hauteur moyenne de 3 à $4 \mathrm{~m}$, ces houles sont particulièrement érosives et peuvent également être à l'origine d'importantes submersions.

- Les houles cycloniques correspondent, quant à elles, à des épisodes très énergétiques, concentrés sur quelques jours par an (de 48 à 72 h), entre novembre et mars. Dépendantes de la trajectoire des cyclones, ces houles s'observent le plus souvent dans les secteurs Nord-Est à Nord-Ouest de l'île et concernent donc particulièrement l'ouvrage. Elles peuvent atteindre une hauteur maximale d'une dizaine de mètres (moyenne de l'ordre de 5 à $7 \mathrm{~m}$ ) pour des périodes variant entre 12 et $16 \mathrm{~s}$. 


\section{XIV èmes Journées Nationales Génie Côtier - Génie Civil \\ Toulon, 29 juin au $1^{\text {er }}$ juillet 2016}

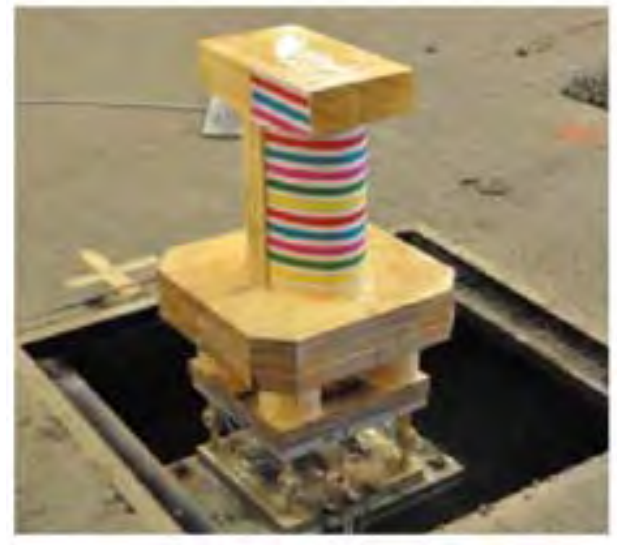

Pile équipée d'une balance pour mesurer les efforts

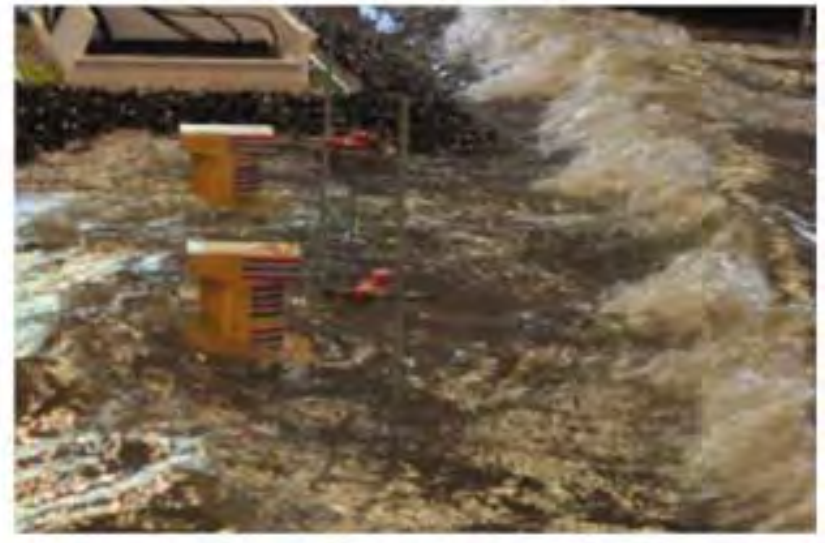

Mesure du niveau d'eau (sonde) et des efforts de houle

Figure 9. Images des essais réalisés au DHI.

Les efforts exercés par la houle sur les piles sont fournis dans le CCTP sur la base d'essais en bassin réalisés par le Maître d'œuvre EGIS (avec l'appui du laboratoire DHI, Danemark). Les résultantes sont les suivantes :

- 1600 T ELS pour la houle cyclonique en service

- 1200 T ELS pour la houle cyclonique en construction (10 ans)

\subsection{Marée}

Dans cette partie de l'Océan Indien, la marée est de type semi-diurne à inégalité diurne (il y a deux cycles de marée par jour mais les hauteurs des pleines mers ou des basses mers consécutives peuvent être très différentes). En temps normal, les variations du niveau de la mer, liées à la marée, sont faibles et ne jouent pas un rôle important dans la dynamique sédimentaire (marée comprise entre 0,10 et $0,90 \mathrm{~m}$ ).

\subsection{Courants}

Les courants caractéristiques du site sont globalement modérés mais présentent des phases d'intensification fortes et fréquentes, qui peuvent être durables. L'influence de la marée est ici nettement atténuée, les courants se propageant vers l'ouest la majorité du temps.

L’ensemble du site présente une relative homogénéité des courants sur la colonne d'eau en termes de vitesse et de direction. Les mesures in situ mettent donc en évidence des courants ayant les caractéristiques suivantes :

- parfois forts, avec jusqu'à plus de $1 \mathrm{~m} / \mathrm{s}$;

- non cisaillés : les courants sont relativement homogènes sur la verticale ;

- relativement symétriques en direction, avec une fréquence similaire à celle de la marée, orientés globalement sud-ouest nord-est, parallèles à la côte ; 


\section{Lecture spéciale}

- sans corrélation forte avec le vent, excepté près de Saint-Denis, puisqu'aucune dérive nettement orientée dans le sens des alizés n’est observée ;

- aucune intrusion de courants généraux n’est clairement mise en évidence (pas de dérive marquée dans un sens ou dans l'autre qui ne puisse être expliquée par l'influence du vent).

\subsection{Choc de bateaux}

La zone du viaduc est interdite de manière permanente à la navigation, mais proche d'une zone de mouillage du Grand Port Maritime de la Réunion. La conception du viaduc, à l'issue d'une analyse statistique, prend en compte la probabilité d'un choc de bateau à la dérive, de moyen tonnage (3000 T à l'ELS).
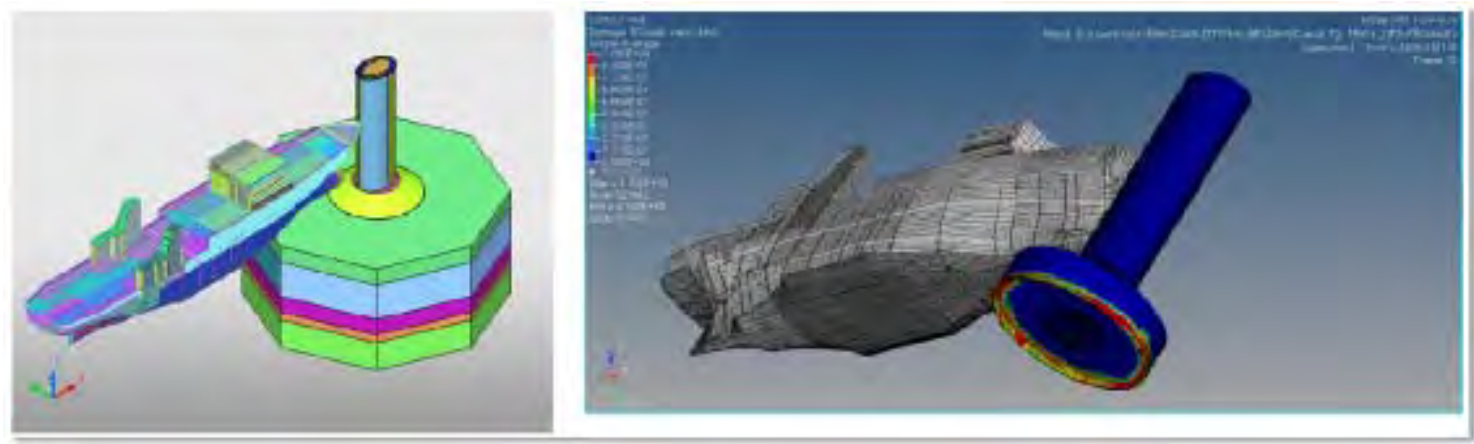

Figure 10. Simulation numérique du choc de bateau.

\section{5 $\underline{\text { Vent }}$}

En moyenne, entre 9 et 10 systèmes tropicaux se forment annuellement sur le bassin Sud-Ouest de l'Océan Indien, dont la moitié atteint le stade de cyclone tropical. La variabilité interannuelle est forte.

Il n'y a pas de relation directe entre cette activité cyclonique globale et le risque cyclonique encouru par la Réunion : une saison de faible activité peut engendrer un cyclone destructeur pour l'île, et inversement celle-ci peut ne connaître aucun cyclone durant une saison très active.

Le CCTP fixe la vitesse de base de référence du vent à $34 \mathrm{~m} / \mathrm{s}$ suivant les indications de la clause 4.25 NA de la norme NF EN 1991-1-4/NA. Les efforts liés au vent ont été déterminés en soufflerie (CSTB à Nantes) sur 2 types de maquette :

- Maquette 2D pour déterminer la portance du tablier ;

- Maquette 3D pour déterminer les efforts sur le fléau et le lanceur (résistance au cyclone en phase de construction). 


\section{XIV ${ }^{\text {èmes }}$ Journées Nationales Génie Côtier - Génie Civil \\ Toulon, 29 juin au $1^{\text {er }}$ juillet 2016}

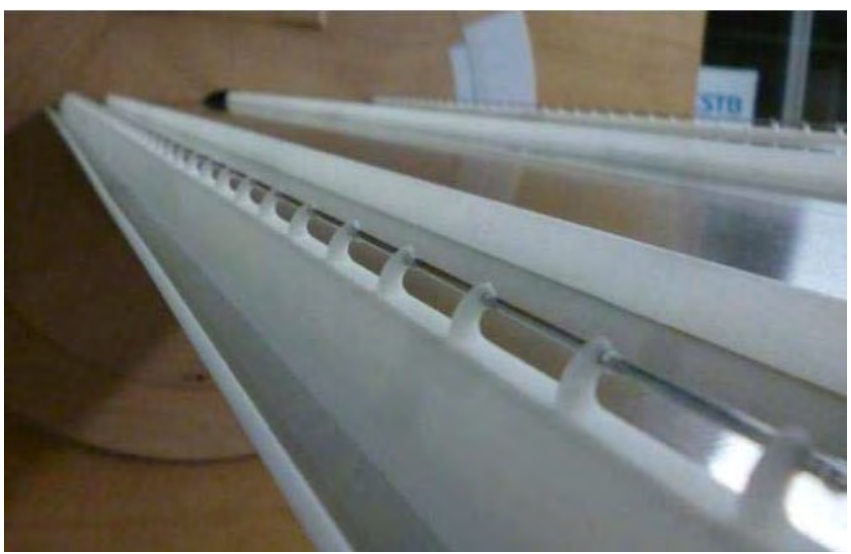

Figure 11. Vue de la maquette 2D.
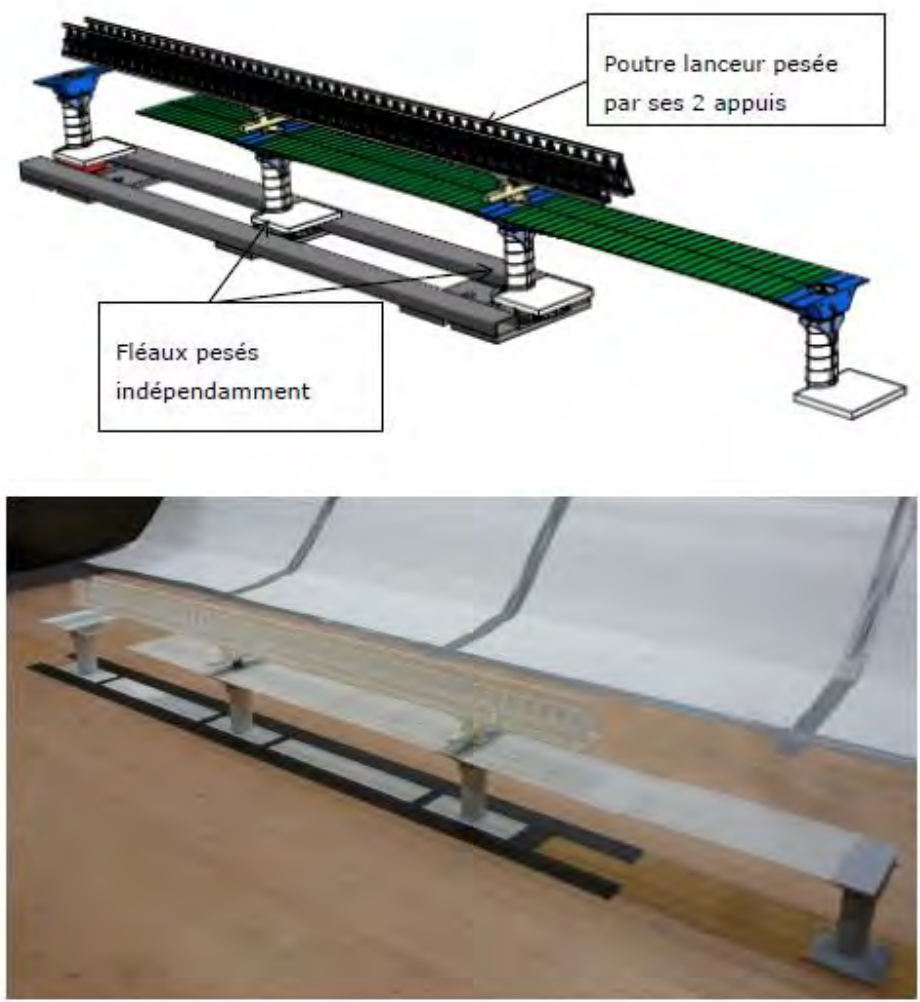

Figure 12. Principe et vue de la maquette 3D.

\subsection{Enjeux environnementaux}

Les fonds rencontrés le long du viaduc, sont en grande majorité sableux et ne représentent un enjeu écologique majeur que dans les rares zones d'affleurement du substrat (formations coralliennes remarquables de la Pointe du Gouffre). Ces formations coralliennes sont situées à proximité de certains appuis mais ne sont pas directement impactées par les travaux d'excavation et de pose. La zone est également réputée pour ses observations de cétacés (dauphins, baleines). 


\section{Lecture spéciale}

D’importantes mesures préventives de protection sont prévues en phase travaux :

- Monitoring visuel et acoustique assuré par EGIS avant le démarrage des travaux ;

- Rideaux anti-MES (matières en suspension);

- Suivi des taux de MES et de turbidité contrôlés en permanence ;

- Lutte contre le bruit sous-marin : réduction préventive des niveaux de bruit des différents ateliers, monitoring acoustique, rideaux à bulles ;

- Dispositions spécifiques vis-à-vis de l'avifaune (éclairage de nuit spécifique).

Les piles situées à proximité de la Pointe du Gouffre seront équipées, sur le site de préfabrication, de structures artificielles favorisant la colonisation par divers organismes marins, afin de renforcer l'attractivité pour la faune des formations coralliennes voisines.

\section{Etudes d'exécution}

\subsection{Reconnaissances géotechniques}

Les reconnaissances réalisées préalablement à la consultation des entreprises comprenaient des mesures bathymétriques (sonar), géophysiques (sismique réfraction, essais de lançage) et géotechniques (sondages carottés, pressiométriques). Ces reconnaissances visaient à reconnaître l'ensemble de la zone (le fuseau des solutions possibles) et non la reconnaissance spécifique de chaque zone de fondation.

Le Groupement d'entreprises a donc réalisé, dans le cadre de son marché, une campagne de reconnaissances par appui qui comprend :

- Une campagne géophysique (mesures de sismique réfraction par flûtes trainées ou coulées) axée sur les appuis définitifs ;

- Une campagne géotechnique effectuée au droit de chaque appui à l'aide d'une barge autoélévatrice munie de différentes machines de sondage (CPT tests, carottages, sondages pressiométriques). 


\section{XIV ${ }^{\text {èmes }}$ Journées Nationales Génie Côtier - Génie Civil \\ Toulon, 29 juin au $1^{\text {er }}$ juillet 2016}

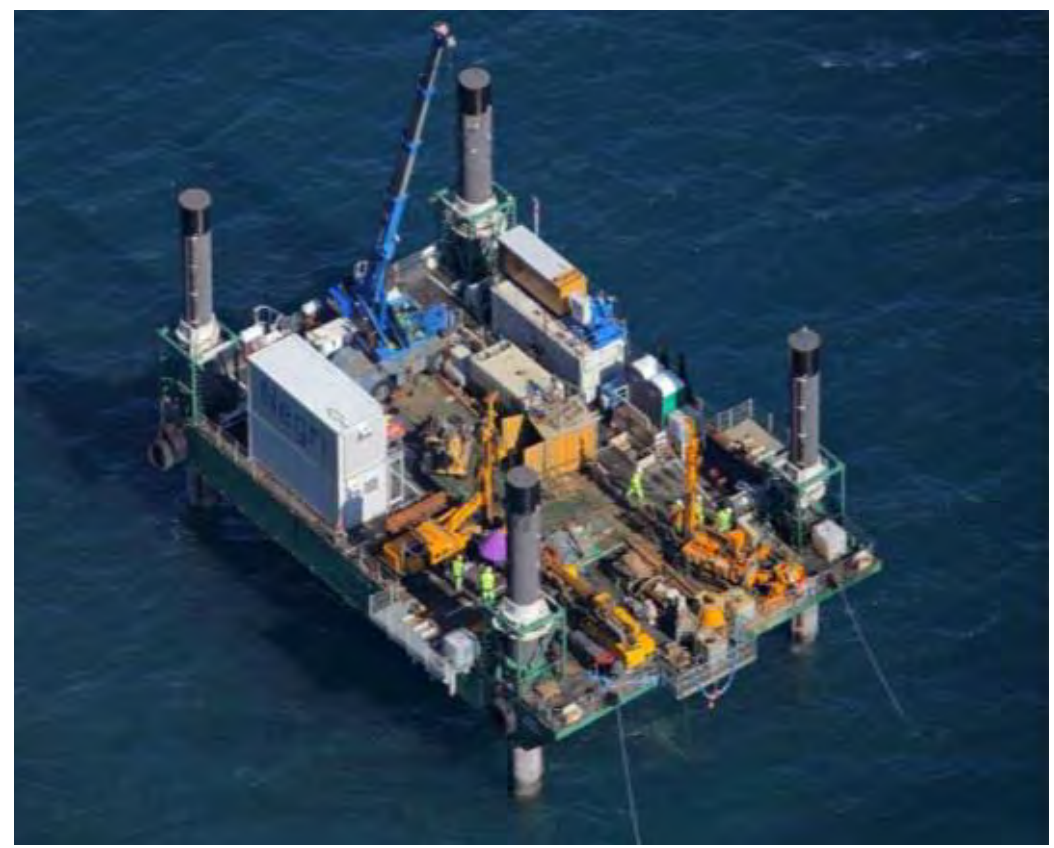

Figure 13. Vue aérienne de la barge de reconnaissances "Adriana".

La succession des couches rencontrées est la suivante :

- Substratum formé de coulées basaltiques de pendage et de profondeur variables ;

- Sables moyennement consolidés, parfois entrecoupés de couches de blocs et galets de grande taille ;

- Sables lâches de surface résultant de l'action des vagues et des courants.

Sur quelques appuis on trouve des zones de gros blocs ou d'éboulis en surface ou sur une profondeur de plusieurs mètres. Enfin une pile (P32) est fondée directement sur un affleurement du substratum basaltique.

\subsection{Choix du type de fondations}

Le Dossier de Consultation des Entreprises prévoyait des fondations superficielles pour environ la moitié des piles, et profondes pour l'autre moitié avec des massifs de pieux de $4 \mathrm{~m}$ de diamètre pour les piles, et de $2 \mathrm{~m}$ de diamètre pour les culées.

$\mathrm{Au}$ cours de la phase d'appel d'offres, le groupement d'entreprises a proposé l'élimination des pieux (sauf pour les 2 culées d'extrémité), sous réserve de confirmation par sondages géotechniques complémentaires et de la possibilité de renforcer les sols au cas par cas.

Outre l'économie substantielle du fait de l'élimination quasi-totale des fondations profondes, les appuis superficiels permettent de :

- réduire le nombre d'ateliers maritimes nécessaires à la réalisation du viaduc ;

- permettre la préfabrication complète des appuis.

- La quasi-totalité du viaduc, appuis et tablier, est ainsi préfabriquée à terre. Les avantages de cette solution sont nombreux : 


\section{Lecture spéciale}

- obtenir une meilleure qualité finale, et une meilleure durabilité (maîtrise des coffrages, du béton) ;

- réduire les impacts sur la sécurité du personnel et sur l'environnement ;

- mécaniser les outils coffrants et atteindre à terme des cycles industriels.

Seules les culées d'extrémités, C0 et C49 sont coulées en place. Les appuis en mer sont préfabriqués en béton armé puis mis en place depuis une barge de travail off-shore, d'une capacité de transport et de levage de 4800 tonnes.

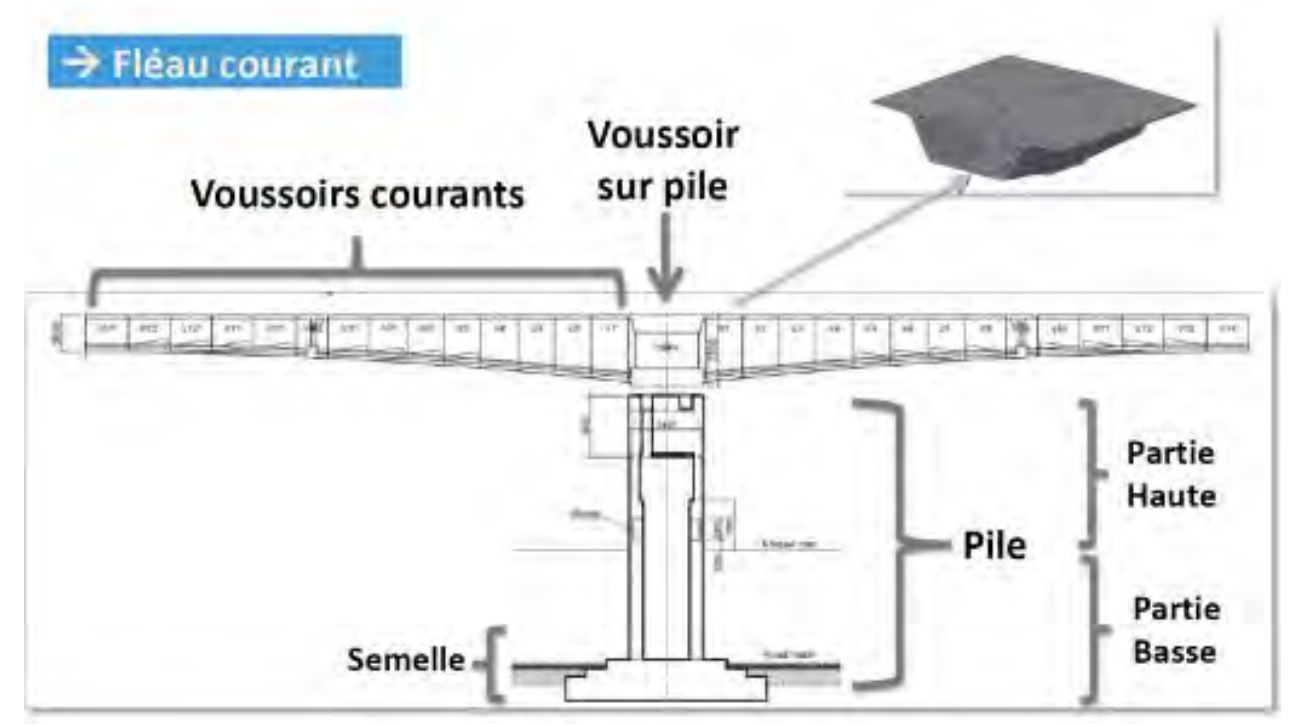

Figure 14. Synoptique des différentes pièces préfabriquées.

\subsection{Conception des piles et piles culées}

Les piles et piles culées sont fondées sur des semelles superficielles circulaires de 20 ou $23 \mathrm{~m}$ de diamètre suivant le type d'appui.

Les semelles de $23 \mathrm{~m}$ correspondent aux 7 points fixes (un par tronçon de viaduc) et aux 6 piles culées pour lesquelles les efforts appliqués (chocs ou houle) sont similaires à ceux des piles courantes alors que les descentes de charge sont plus faibles. Les 35 piles courantes ont une semelle de diamètre $20 \mathrm{~m}$.

Ces fondations s'appuient sur les couches de sol compact, à l'exception de la pile P32 fondée sur le substratum (basalte). Les zones sableuses présentant des faiblesses sont consolidées par la méthode de vibroflottation.

L'ensemble pile-fondation (appui) est réalisé en deux parties. La partie inférieure, dite "embase" comprend la semelle et la partie inférieure du fût de pile permettant d'atteindre une cote d'environ $3 \mathrm{~m}$ au-dessus du niveau d'eau. La partie supérieure "tête de pile" comprend la partie haute du fût et le chevêtre. Les deux parties sont reliées entre elles par un joint de clavage de 1,5 m de hauteur. 


\section{XIV ${ }^{\text {èmes }}$ Journées Nationales Génie Côtier - Génie Civil \\ Toulon, 29 juin au $1^{\text {er }}$ juillet 2016}

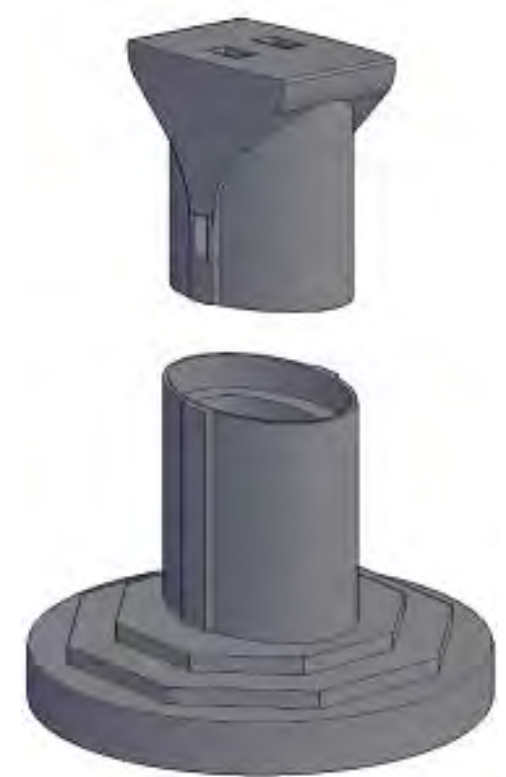

Figure 15. Principe de réalisation d'un appui.

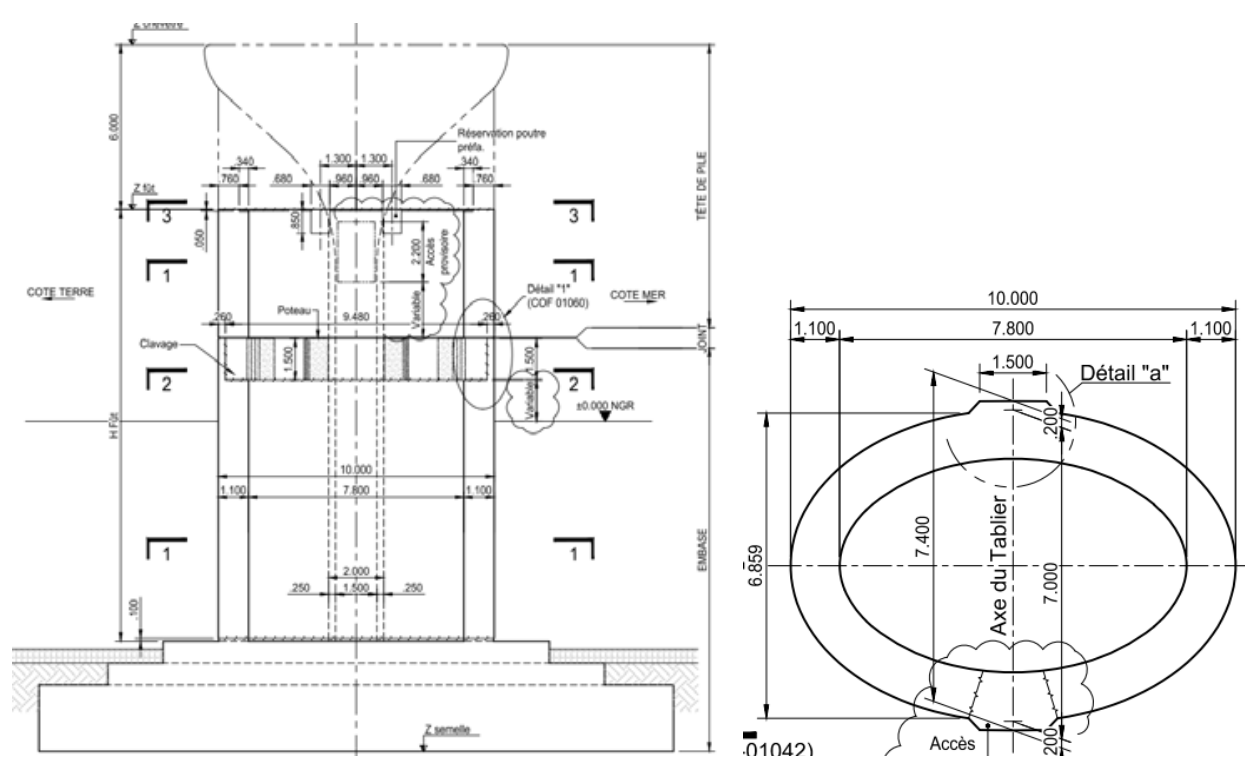

Figure 16. Elévation des piles et des fondations et coupe en section courante.

Les semelles circulaires font 2,40 m d'épaisseur. Elles sont surmontées de 2 podiums octogonaux de 0,8 m d'épaisseur chacun. Le fût de pile est creux, de forme elliptique de grande base $10 \mathrm{~m}$ et de petite base 7,4 m, d'épaisseur constante 1,1 m. Une nervure architecturale court le long du fût sur chaque face de la grande base de l'ellipse.

Les embases sont équipées d'un système de protection cathodique destiné à protéger de la corrosion les parties de l'ouvrage situées dans la zone d'immersion et dans la zone de marnage. 


\section{Lecture spéciale}

Les chevêtres, préfabriqués avec la partie supérieure du fût, assurent la transition entre la forme ellipsoïdale du fût et la tête de pile par l'intermédiaire de l'épanouissement du bossage du fût. Le chevêtre pour pile courante et fixe a une largeur de $11.00 \mathrm{~m}$, le chevêtre de pile culée une largeur de $14.50 \mathrm{~m}$.

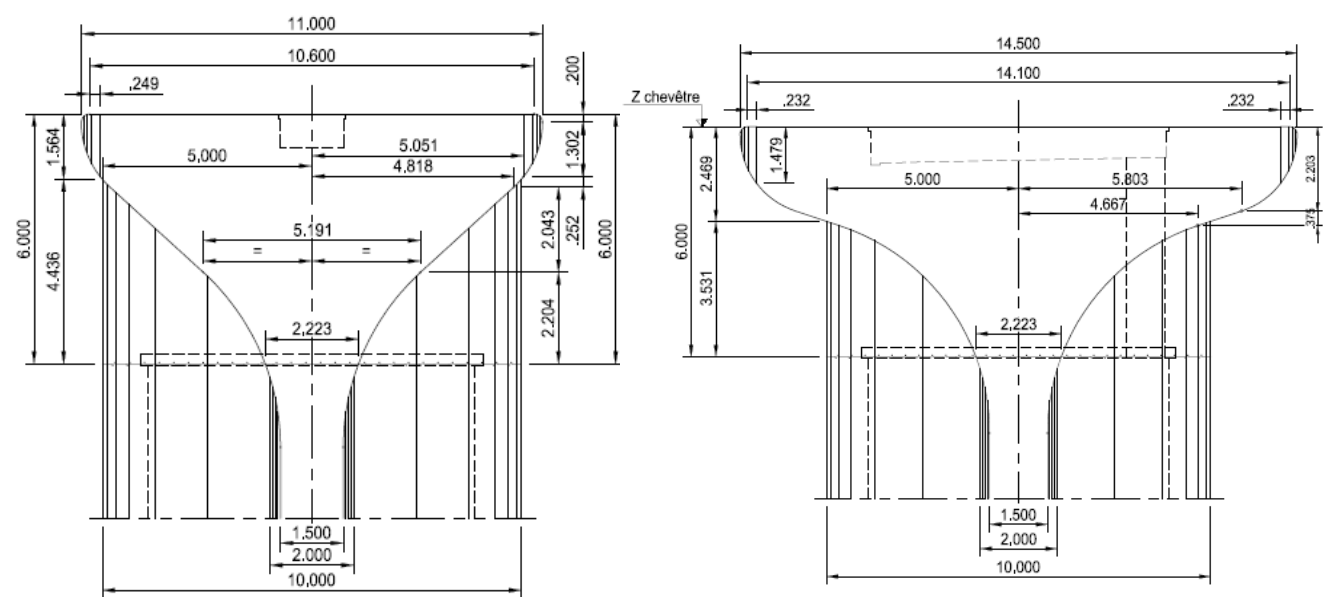

Figure 17. Elévations du chevêtre de pile courante et de pile fixe.

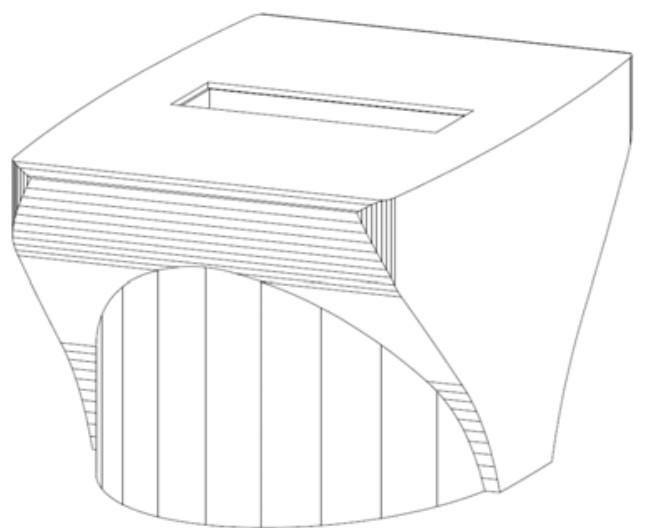

Figure 18. Axonométrie du chevêtre de la pile fixe, hors bossages.

La tête de pile comprend les appareils d'appuis, les réservations nécessaires à la construction (zones de cales, passage des câbles de clouage et levage) et une "baignoire" placée à l'axe pour les besoins de visite et de maintenance.

\subsection{Culées}

Les culées permettent le raccordement de la partie digue à la partie viaduc. Elles sont fondées sur 26 pieux de diamètre Ø1000. L’important remblai (14 m) monté après leur réalisation génère des efforts significatifs dans ces pieux.

L'utilisation de fondations profondes pour ces culées résulte notamment de leur position semi-perchée (base de la culée à la cote +6.00 NGR) : les pieux permettent de garantir 


\section{XIV ${ }^{\text {èmes }}$ Journées Nationales Génie Côtier - Génie Civil \\ Toulon, 29 juin au $1^{\text {er }}$ juillet 2016}

l'intégrité de la culée même en cas de mouvement significatif du musoir d'extrémité des digues sur lesquelles elles sont bâties.

Le sommier solidarisant les têtes des pieux est surmonté d'une boîte parallélépipédique de dimensions 39,50 m×10 m sur $14 \mathrm{~m}$ de haut environ. Cet ouvrage de génie civil intègre les appuis du voussoir sur culée (VSC), les raccordements aux murs délimitant le remblai de la digue (mur incliné côté terre, mur chasse-mer côté océan), les murs garde-grève et dalles de transition, les dispositifs de recueil des eaux des corniches caniveaux et les réservations pour le passage des réseaux.

\subsection{Tablier}

Le tablier est constitué d'un seul caisson à deux âmes en béton précontraint. Il est totalement préfabriqué, et les joints entre voussoirs sont conjugués.

Le tablier est de hauteur variable de $7.3 \mathrm{~m}$ sur appui (VSP) à $3.8 \mathrm{~m}$ au milieu de la travée (à la clé) suivant une loi polynomiale.

Le hourdis supérieur est d'épaisseur variable de $0,3 \mathrm{~m}$ à $0,6 \mathrm{~m}$. Il est précontraint transversalement dès la préfabrication par des câbles 4T15 en torons gainés-graissés pour limiter les différentiels de flèches entre hourdis de voussoirs successifs, et ainsi préserver la conjugaison.

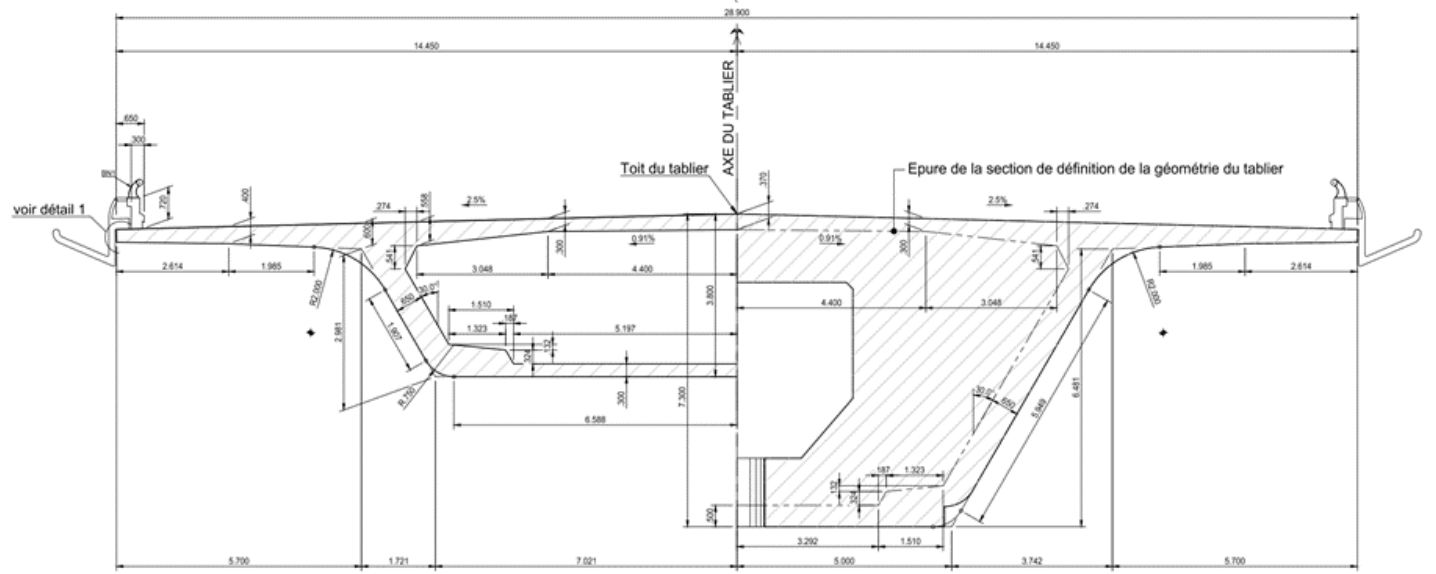

Figure 19. Demi-coupe à la clé et sur pile.

Les âmes ont une épaisseur de 0,65 m. Elles sont inclinées de $30^{\circ}$ sur la verticale ce qui est peu commun dans ce type d'ouvrages et ce qui conduit à des largeurs du hourdis inférieur variables de $14 \mathrm{~m}$ à la clé à $10 \mathrm{~m}$ sur appui. L'épaisseur du hourdis inférieur est variable longitudinalement de $0,5 \mathrm{~m}$ à $0,3 \mathrm{~m}$.

La segmentation a été choisie pour s'accorder aux capacités des méthodes de levage, à la fois sur la zone de préfabrication (portique de levage) et sur la zone de pose (barge et lanceur). Un demi-fléau se compose de 14 voussoirs de travée courante, de longueur 4,015 m, reliés au voussoir sur pile (VSP), décomposé en trois parties pour une 


\section{Lecture spéciale}

longueur totale de 7,30 m. Cette segmentation du VSP répond à la contrainte des capacités de levage sur le site de préfabrication afin de permettre le coulage en conjugaison du voussoir $n^{\circ} 1$.

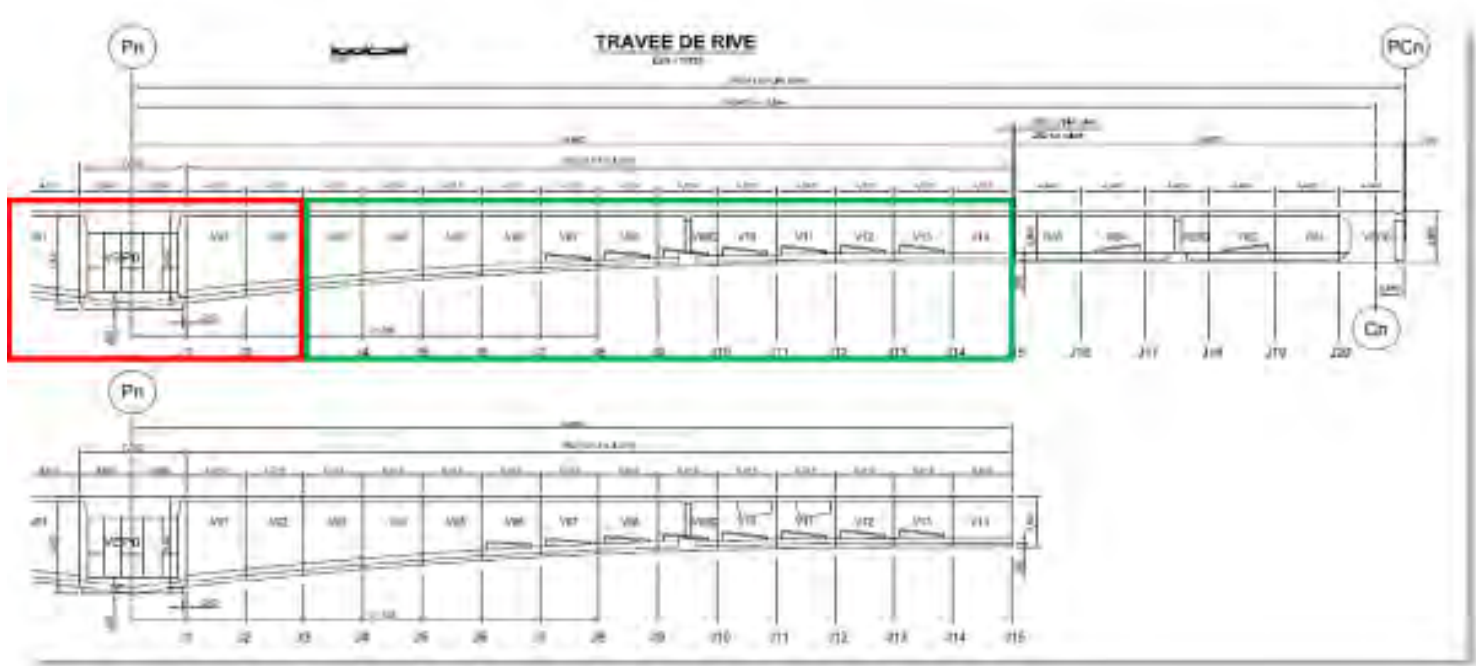

Figure 20. Segmentation en travée courante (demi-fléau).

En travée de rive, le voussoir sur culée ou de pile culée, long de 4,30 m, réalisé en un seul élément, est assemblé à cinq voussoirs de rive longs respectivement de 4,275 m, $3 \times 4,400 \mathrm{~m}, 4,275 \mathrm{~m}$ soit 26,30 m. Cet ensemble est lié au premier et au dernier fléau de chaque tablier par un joint de clavage de $0,25 \mathrm{~m}$.

Le VSP est complété sur la zone de préfabrication avec les 2 premiers voussoirs V1 et V2 qui y sont assemblés de chaque côté pour constituer le méga VSP (MVSP), d'une longueur totale de $23.360 \mathrm{~m}$.

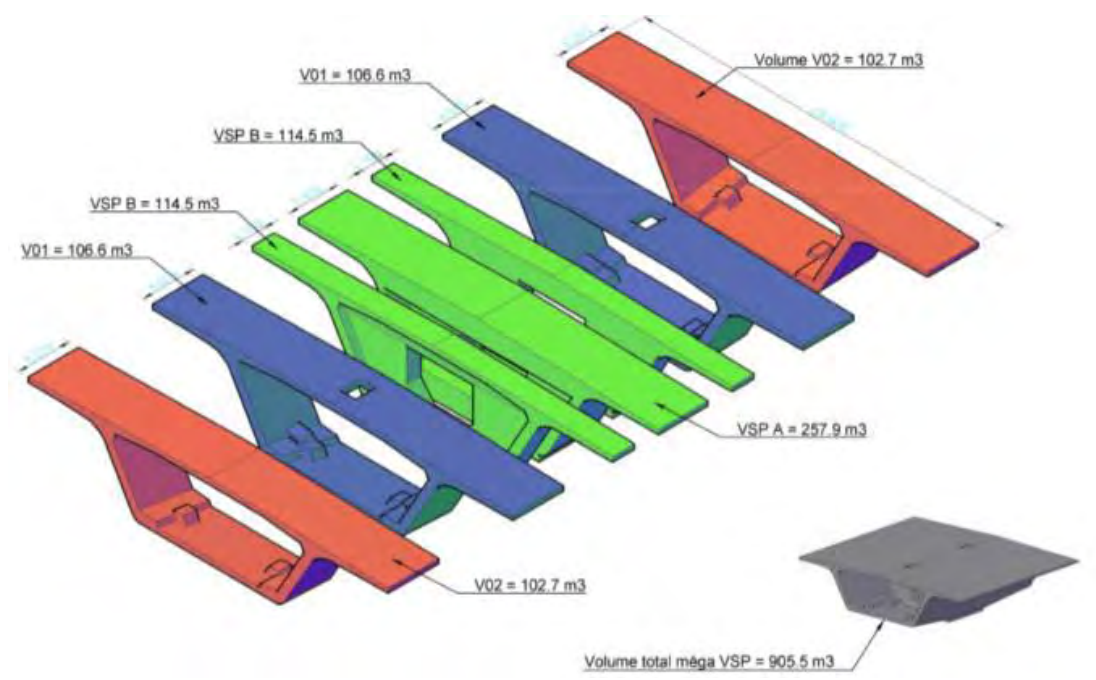

Figure 21. Décomposition du VSP (en vert) et du MVSP. 


\section{XIV ${ }^{\text {èmes }}$ Journées Nationales Génie Côtier - Génie Civil \\ Toulon, 29 juin au $1^{\text {er }}$ juillet 2016}

La précontrainte longitudinale est de type mixte, c'est-à-dire en partie intérieure pour assurer la stabilité en construction, et extérieure pour les phases d'exploitation. Deux déviateurs sont donc introduits par travée courante de même qu'en travées de rive. Les dimensionnements en phase d'exploitation tiennent compte des modes d'exploitation décrits : mode 1 , $2 \mathrm{a}$ et $2 \mathrm{~b}$.

Le câblage de précontrainte du fléau est constitué de 20 câbles actifs par âme en 31T15S. Les câbles éclisses inférieurs en 37T15S au nombre de 7 par âme du voussoir V7 au voussoir V13 sont complétés par 1 câble éclisse supérieur au voussoir V11. Enfin les câbles extérieurs sont aussi en 37T15S. On en trouve 6 par âme dans toutes les travées (y compris les travées de rive), (voir figures 22, 23 et 24).

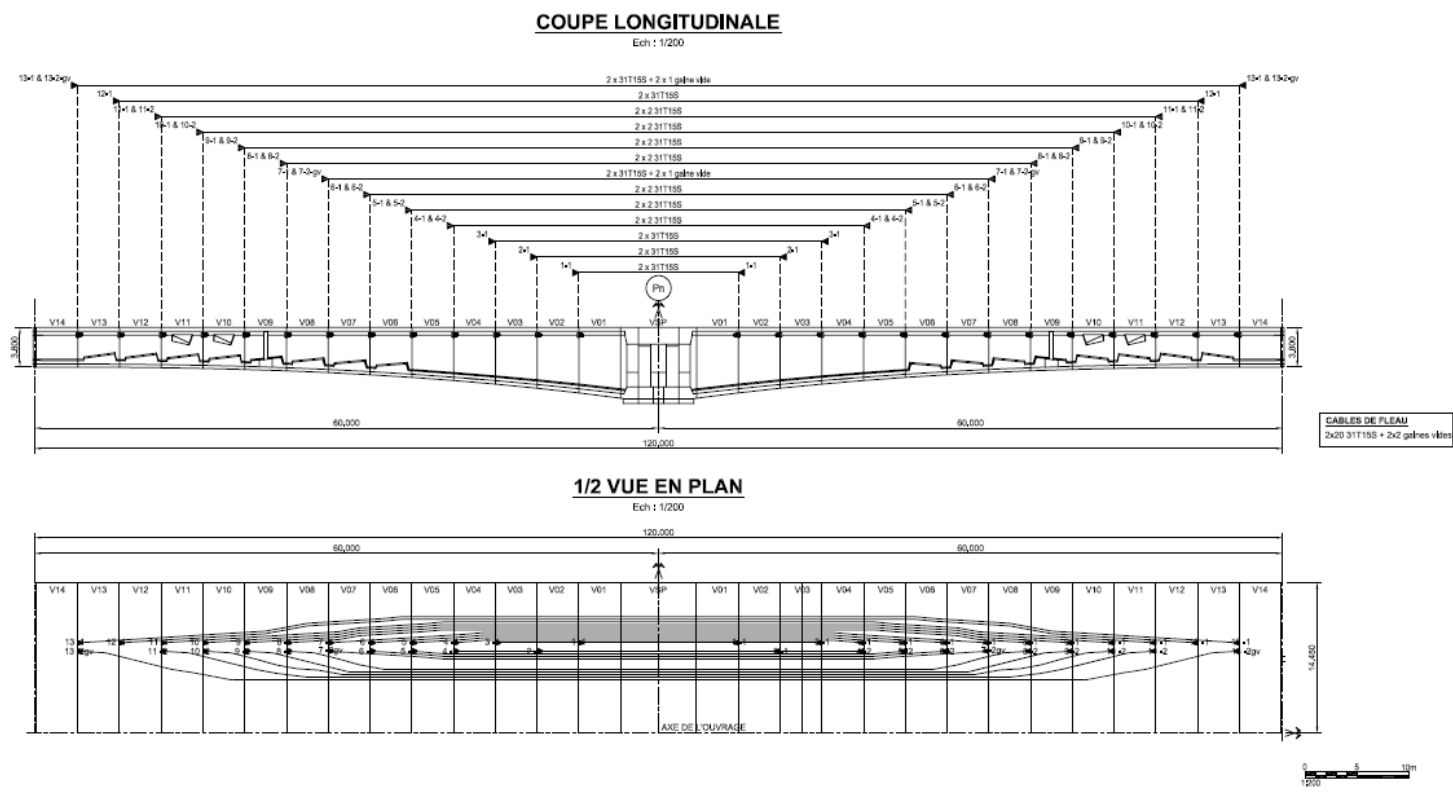

Figure 22. Principe de la précontrainte de fléau.

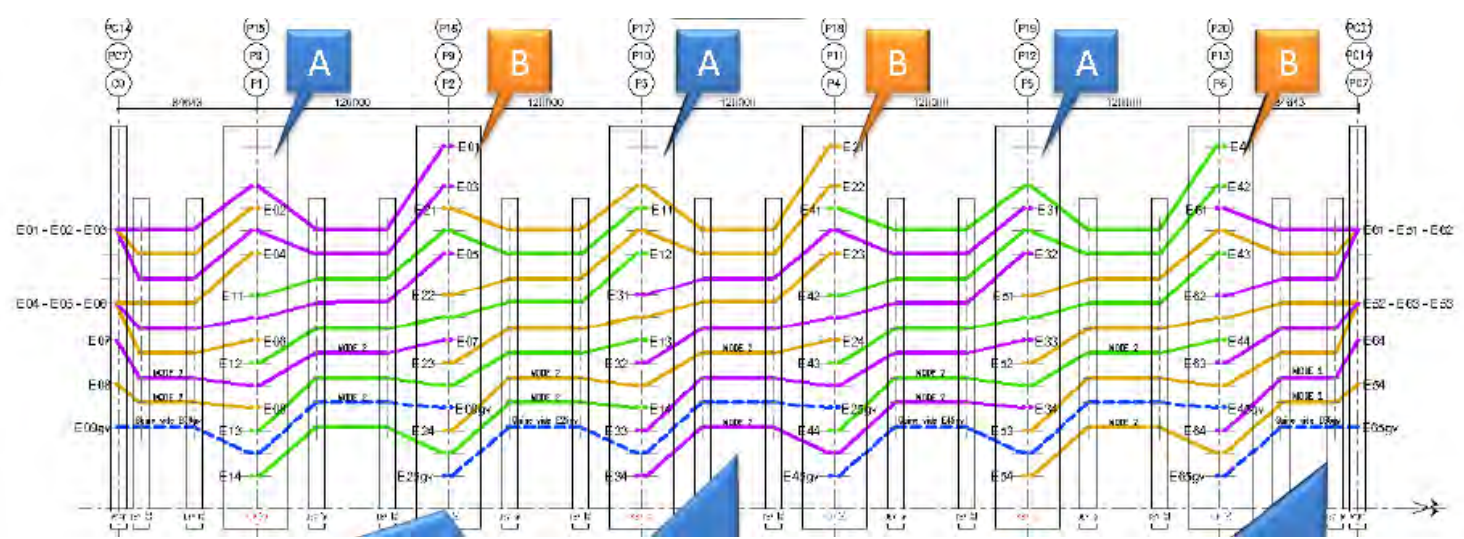

Figure 23. Principe de la précontrainte de continuité. 


\section{Lecture spéciale}

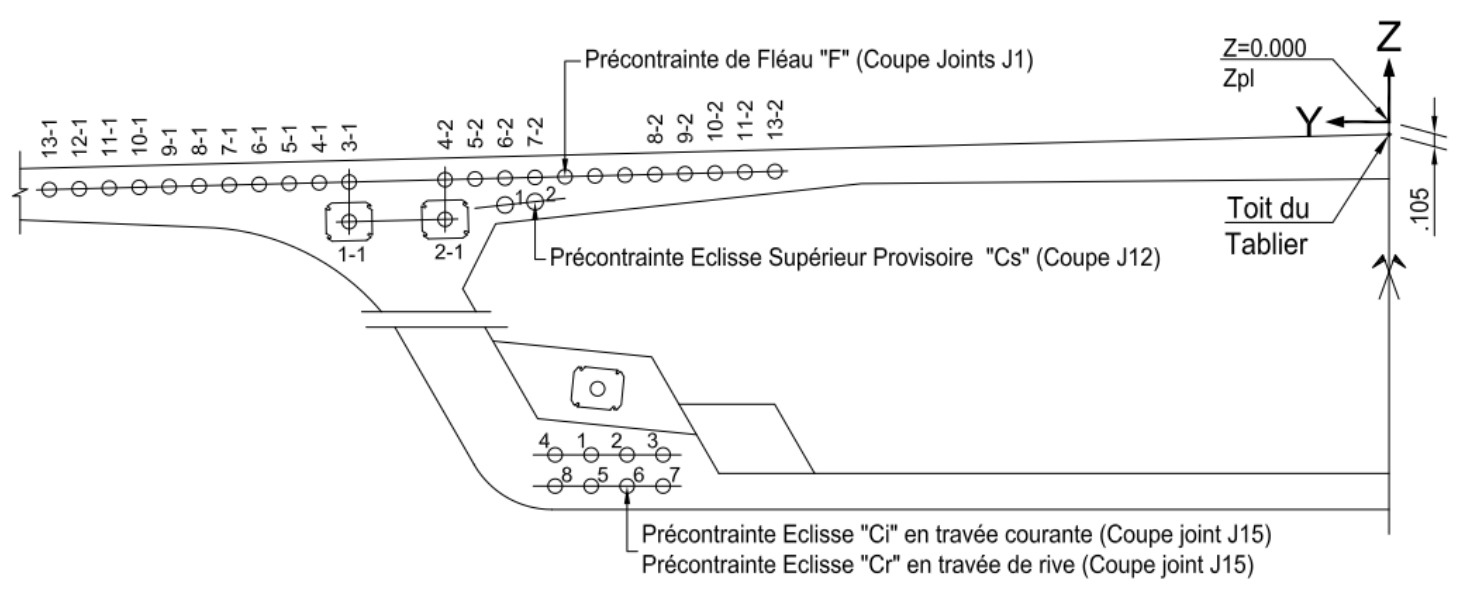

Figure 24. Principe général du masque de précontrainte.

\subsection{Protection anti-affouillement}

Le choix de fondations superficielles rend cruciale la qualité de la protection antiaffouillement, un déchaussement de l'assise de la pile pouvant compromettre la stabilité de l'ouvrage. Par ailleurs l'entretien de cette protection doit être minimal durant la vie de l'ouvrage compte tenu des difficultés d'intervention dans la zone.

Le marché prévoit 2 solutions pour éviter les affouillements en pied des piles :

- Solution 1 : tapis anti-affouillement constitué d'un géotextile de filtration sur lequel sont fixés des blocs en béton lisse avec un faible espacement entre blocs, masse surfacique du tapis de $1000 \mathrm{~kg} / \mathrm{m}^{2}$;

- Solution 2 : mise en place au fond d'une souille d'un complexe constitué :

- D’un géotextile de filtration ;

- D’une sous-couche en tout-venant 100-300 kg, d'épaisseur 1,00 m ;

- De deux couches d'enrochements 2-4 T, d'épaisseur 2,45 m.

- Le diamètre de la zone traitée dans les deux solutions est de $50 \mathrm{~m}$ (5 fois le diamètre des piles).

La solution 2 a été étudiée par le maître d'œuvre EGIS sur modèle physique 3D en cuve à houle au laboratoire DHI.

La solution 1 a fait l'objet d'un programme d'essais hydrauliques réalisé par le groupement d'entreprises sous la supervision du cabinet Jean Bougis. Ce programme était le suivant :

- Essais 2D en canal à houle (canal ACRI-IN à Sophia-Antipolis) : ces essais au 1/50e sur fond fixe ont permis de confirmer l'ordre de grandeur de la masse surfacique des blocs (de l'ordre de $40 \mathrm{~cm}$ de béton soit $1000 \mathrm{~kg} / \mathrm{m}^{2}$ ) et de préciser certains critères géométriques améliorant la stabilité du tapis (régularité du pavage, rapport de forme des blocs, géométrie du bord du tapis, voir figure 25).

- Essais 3D en bassin (bassin TOD de l'IHLAB à Santander) : ces essais au 1/35e sur fond mobile ont permis d'étudier les effets liés à l'érosion ainsi qu'aux variations de 


\section{XIV èmes Journées Nationales Génie Côtier - Génie Civil \\ Toulon, 29 juin au $1^{\text {er }}$ juillet 2016}

divers paramètres (période de retour de la houle, incidence de la houle, durée de l'événement cyclonique, variations en période de la houle, déferlement dans la zone des tapis).

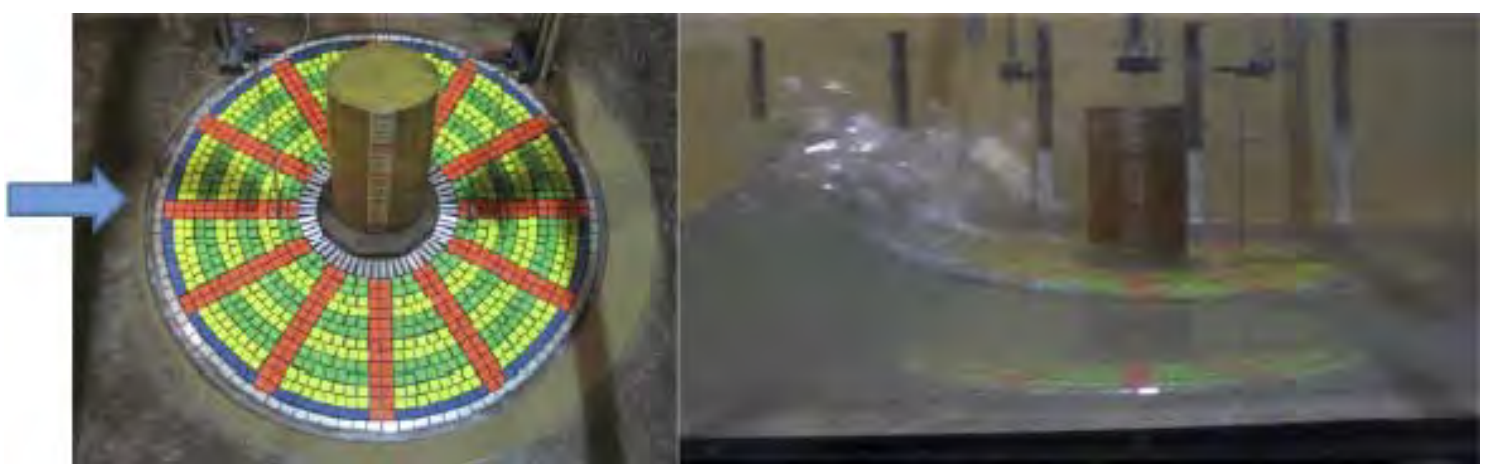

Figure 25. Vue en plan d'un modèle et extrait vidéo d'un essai en canal.

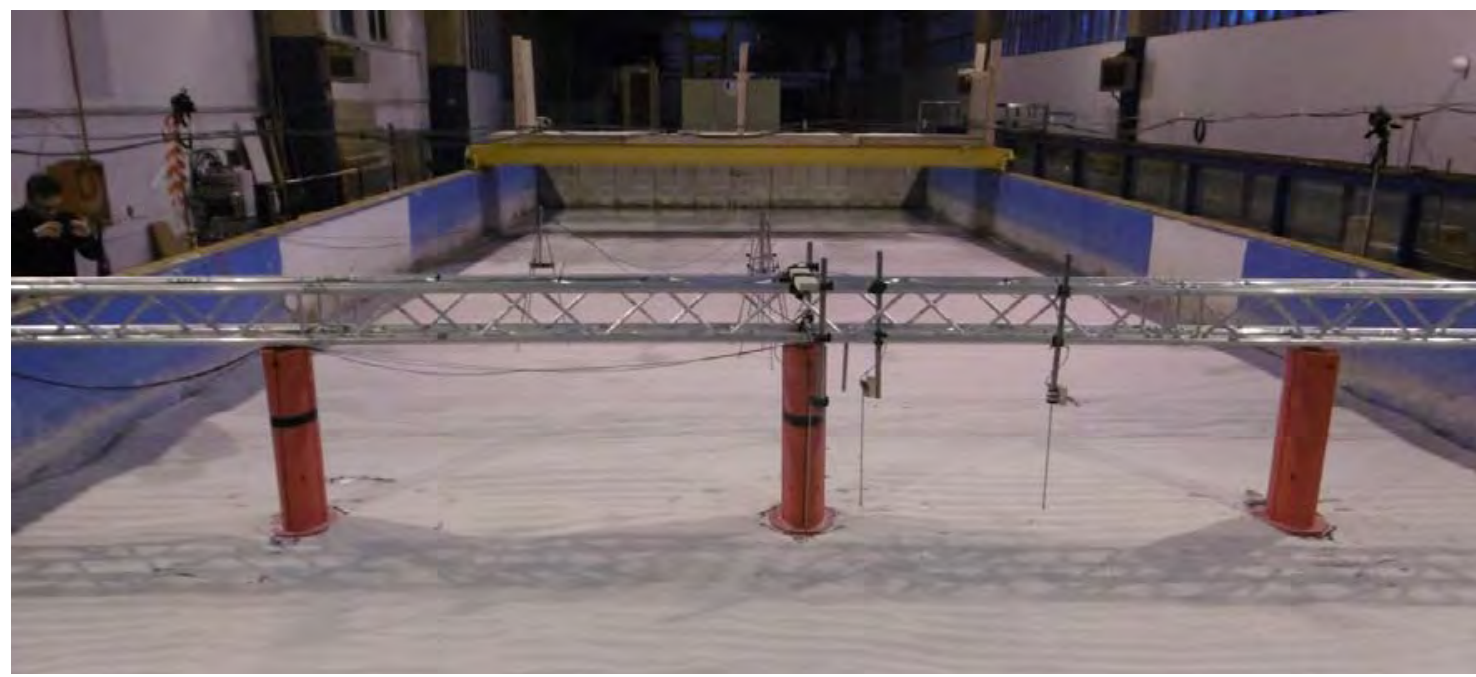

Figure 26. Vue du bassin pendant les essais (les batteurs sont au fond).

Le compte-rendu de ces essais est en cours de rédaction. On peut retenir les conclusions provisoires suivantes :

- Le tapis anti-affouillement n’est pas affecté par les houles cycloniques de retour inférieur à 25 ans ;

- Pour des houles de retour supérieur ou égal à 25 ans (période $T p=13.8 \mathrm{~s}$, hauteur $\mathrm{HmO}=9.5 \mathrm{~m}$ à $-40 \mathrm{NGR}$ ), un fossé d'érosion se forme en avant et en arrière du tapis dans la direction de l'onde incidente (la réflexion sur les ouvrages de la route existante était modélisée). Le bord du tapis plonge dans ce fossé d'érosion, ce qui aboutit à la création d'un profil stable, qui n'est remis en question, ni par l'accumulation d'états de mer successifs, ni par les variations de paramètres (incidence, période, durée d'exposition). 


\section{Lecture spéciale}

- Dans ces conditions, la tenue des liens entre blocs est primordiale. Les efforts de tension dans les câbles reliant les blocs ont été mesurés sur la maquette afin d'en déduire un dimensionnement à l'échelle du prototype.

- La robustesse du tapis est bonne dans la mesure où des endommagements volontaires préalables du tapis ne conduisent pas à l'instabilité des parties restantes du tapis (voir figure 27).

Le Groupement d'entreprises entend donc, en fonction des résultats du rapport d'essai définitif, soumettre le principe de protection anti-affouillement par tapis béton à l'accord du maître d'œuvre EGIS.

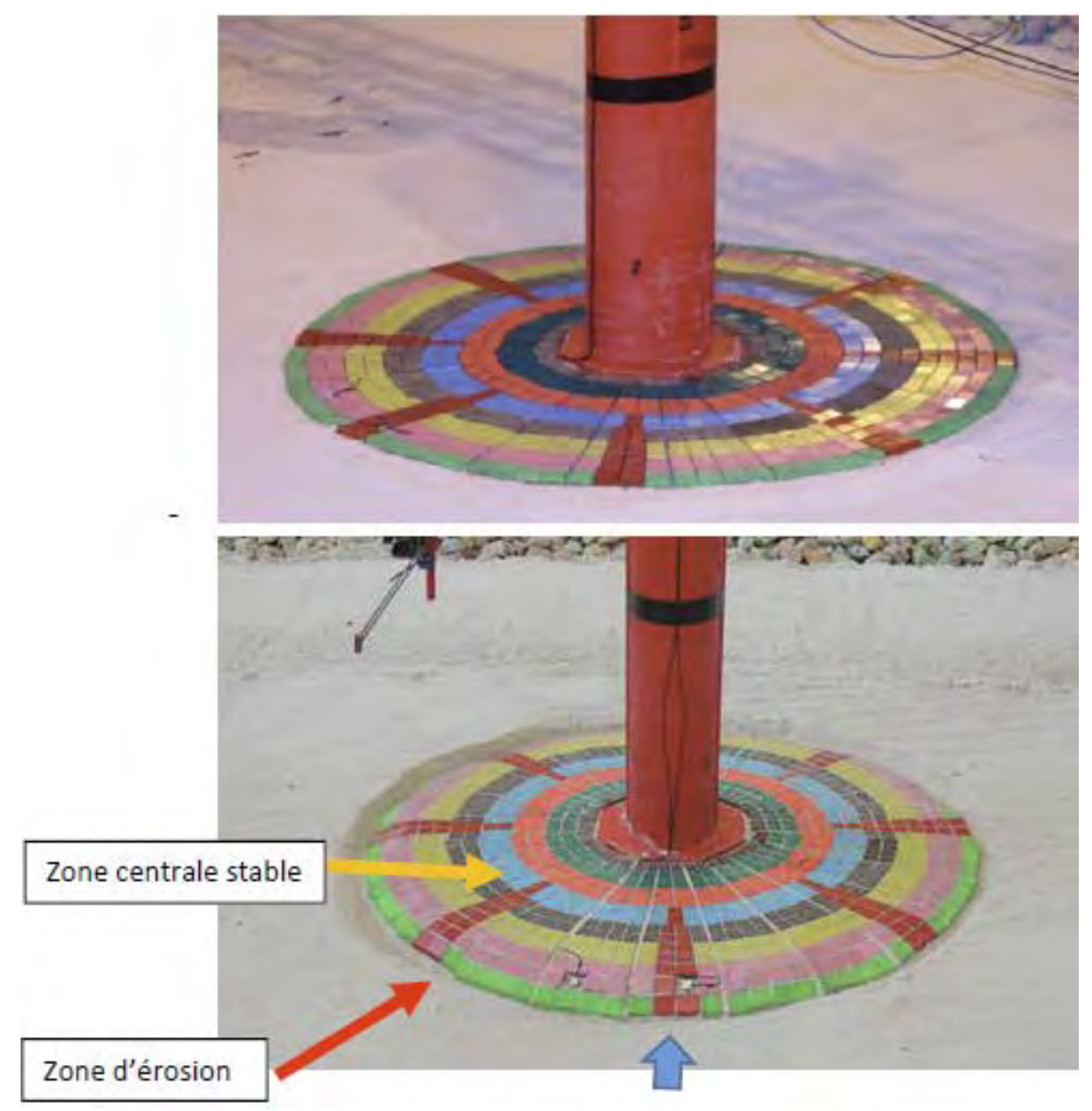

Figure 27. Vue d'un tapis avant et après houle cyclonique. 


\section{XIV èmes Journées Nationales Génie Côtier - Génie Civil \\ Toulon, 29 juin au $1^{\text {er }}$ juillet 2016}

\section{Phasage et méthodes de réalisation}

\subsection{Amélioration des sols}

L'amélioration des sols n'est nécessaire que pour une dizaine de piles, correspondant à des zones où les sables lâches sont trop profonds pour pouvoir être éliminés (limite de dragage au dipper, environ $7 \mathrm{~m}$ sous le $\mathrm{TN}$ ), ou à des zones d'anomalies géotechniques localisées.

Un pré-terrassement visant à enlever une couche de blocs et galets pouvant faire obstacle au passage de l'aiguille vibrante pourra être réalisé au préalable si nécessaire. L'amélioration proprement dite sera effectuée par vibroflottation, à l'aide d'un atelier autonome constitué d’une grue de 250T avec aiguille vibrante montée sur un ponton de $80 \mathrm{~m}$. Un apport de matériaux de ballast $30-80 \mathrm{~mm}$ sera effectué en fonction de la teneur en fines et/ou du confinement de la couche de sable à améliorer. La maille de vibroflottation est déterminée appui par appui en fonction d'objectifs d'amélioration des caractéristiques géotechniques résultant des notes de calcul de stabilité.

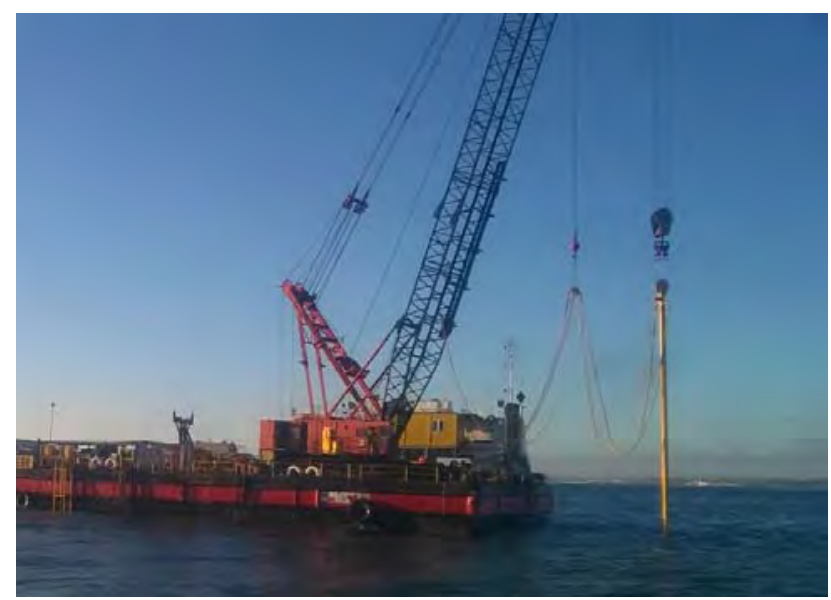

Figure 28. Illustration d'un autre projet de vibroflottation maritime.

\subsection{Excavation et protection des fouilles par mise en œuvre de la couche d'assise}

L'excavation est réalisée par le dipper PINOCCHIO de la société SDI, équipé d'une pelle de $400 \mathrm{~T}$. Elle consiste en la réalisation d'une fouille de base octogonale dont le rayon dépasse de $2 \mathrm{~m}$ le diamètre de la semelle à poser. Les pentes théoriques de l'excavation sont de $3 \mathrm{H} / 1 \mathrm{~V}$ dans les sables meubles, et de $1 \mathrm{H} / 1 \mathrm{~V}$ dans les sols compacts ou blocs rocheux. 


\section{Lecture spéciale}

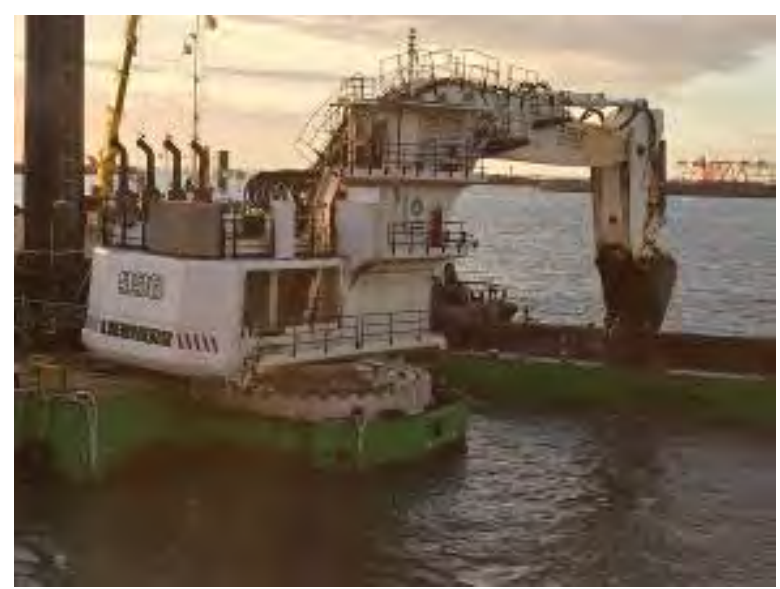

Figure 29. Le dipper PINOCCHIO.

Les fouilles excavées sont immédiatement protégées par la mise en œuvre d'un matériau d'assise composé :

- Soit d'une seule couche de matériau 30-80 mm d'une épaisseur minimale de $1 \mathrm{~m}$;

- Soit d'une couche inférieure filtre de 2-30 mm de $50 \mathrm{~cm}$ d'épaisseur surmontée d'une couche de matériau d'assise $30-80 \mathrm{~mm}$ de $50 \mathrm{~cm}$ d'épaisseur.

Le choix du type d'assise (monocouche ou bicouche) s'effectue en fonction de la caractérisation des matériaux composant le $\mathrm{TN}$ au niveau de la fondation (galets et cailloux dans le premier type, sables grossiers pour le second) à partir des échantillons remontés au droit de chaque appui lors de la campagne de reconnaissances. Il permet de s'assurer du respect des règles de filtre.

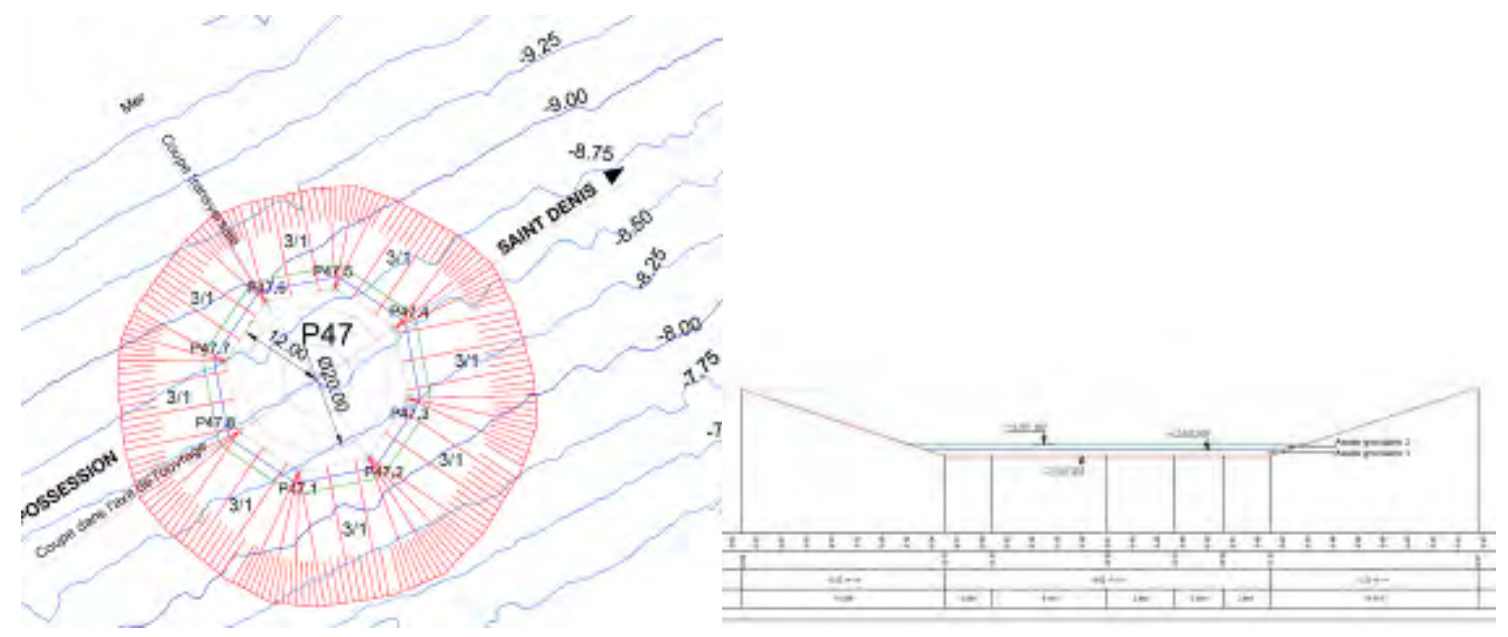

Figure 30. Vue en plan et coupe de principe de l'excavation.

\subsection{Maîtrise des bétons}

Pour assurer une durabilité des bétons à 100 ans dans un environnement très agressif, le marché a prévu l'utilisation de la nouvelle approche performantielle des bétons 


\section{XIV èmes Journées Nationales Génie Côtier - Génie Civil \\ Toulon, 29 juin au $1^{\text {er }}$ juillet 2016}

introduite dans la norme NF EN 206-1/CN, en s'appuyant sur la définition d'indicateurs de durabilité du béton. La mise au point des bétons de structure a nécessité la mobilisation d'experts issus des entreprises et de laboratoires indépendants, et l'utilisation de modélisations spécifiques corrélées à de nombreux essais.

Le Groupement d'entreprises a fait le choix d'une fabrication en propre des bétons de structure du viaduc, afin de maîtriser la production de béton tant en qualité qu'en quantité.

En qualité, il s'agit notamment de maîtriser :

- L’approvisionnement en granulats et ciments locaux ;

- Les critères de durabilité imposés par l'exposition des bétons au milieu marin :

- Diffusion des ions chlorure ;

- Perméabilité.

- Les critères de mise en œuvre (enrobages) ;

- Le développement thermique du béton (maîtrise de la RSI).

En quantité, les cadences à tenir sont de l'ordre de $1500 \mathrm{~m}^{3} /$ jour en pointe.

Trois centrales à béton situées sur l'aire de préfabrication des voussoirs assurent l'ensemble de la production de béton de structure. Les silos à ciment, à additifs et à agrégats sont communs aux trois centrales. Un système de refroidissement par circulation d'eau réfrigérée assure le maintien en température et la saturation des granulats. Il sera complété par une centrale à glace lors des pics de température de l'été austral.

Le projet est également doté de son propre laboratoire, équipé pour effectuer aussi bien les essais classiques sur éprouvettes béton (résistance à la compression) que les essais moins courants liés aux critères de durabilité (mesures de la diffusion apparente des ions chlorure et de la perméabilité aux gaz).

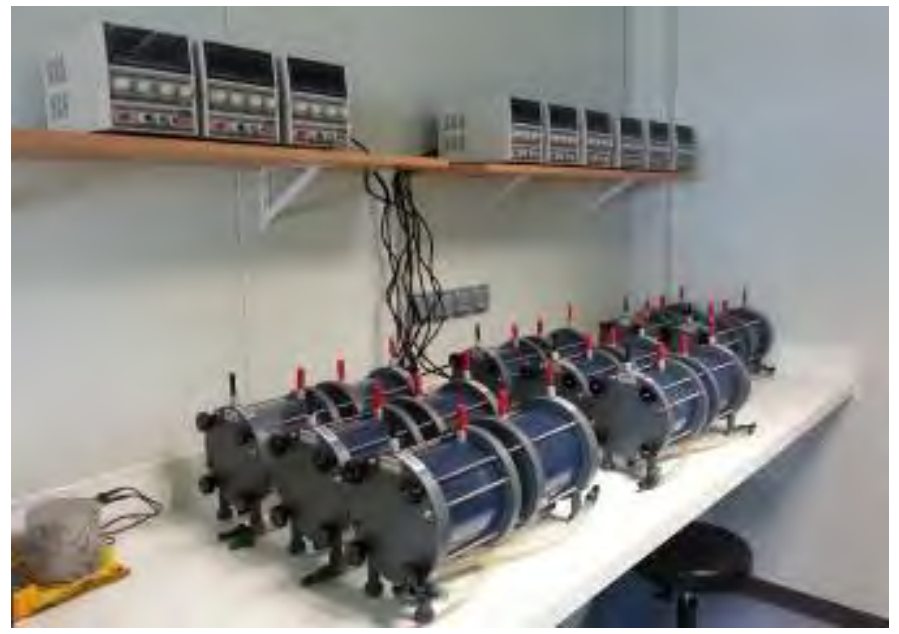

Figure 31. Laboratoire de chantier (cellules de mesure de la diffusion apparente). 


\section{Lecture spéciale}

\subsection{Préfabrication des appuis}

Comme exposé précédemment, la préfabrication quasi-totale des appuis est rendue possible par le passage en fondations superficielles. Les dimensions et les poids des pièces à préfabriquer sont conséquents :

- Pour les "embases" comprenant la semelle et la partie inférieure du fût de pile (jusqu'à la cote $+3,00 \mathrm{NGR}$ ) : poids compris entre $3500 \mathrm{~T}$ et $4500 \mathrm{~T}$, hauteur variant de 15 à $18 \mathrm{~m}$, diamètre de base 20 ou $23 \mathrm{~m}$;

- Pour les "têtes de pile" comprenant le chevêtre et la partie supérieure du fût de pile : poids compris entre $1250 \mathrm{~T}$ et $2250 \mathrm{~T}$, hauteur comprise entre $9 \mathrm{~m}$ et 21,5 m.

Une autre caractéristique, liée à l'absence de dry dock et au manque de superficie portuaire à la Réunion, est que ces pièces sont réalisées "en air", l'embase n'étant immergée qu'au droit de sa position définitive ; ce qui représente un challenge lié au poids et à la taille des pièces à manipuler.

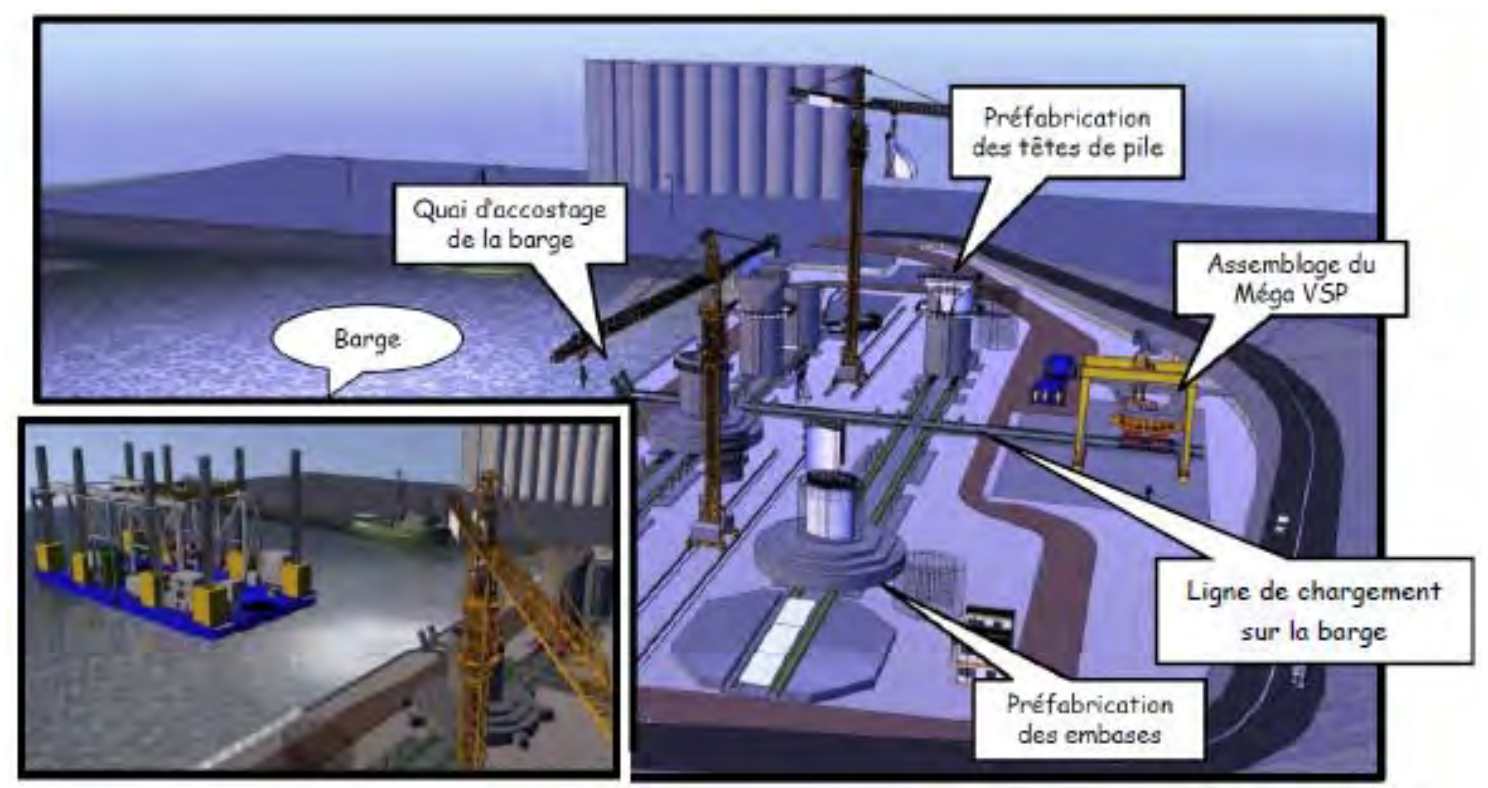

Figure 32. Principe de fonctionnement de l'aire de préfabrication des piles.

L'aire de préfabrication s’organise autour de deux "lignes" de préfabrication implantées au fond du Port Est, et d'une "ligne" de chargement orientée à 90 (figure 33). Sur chaque ligne de préfabrication, les pièces sont préfabriquées selon des positions successives convergeant vers la ligne de chargement centrale :

- $1^{\text {ère }}$ position (dite "podium") : ferraillage et coulage de la semelle (pour les embases), du fût de pile (pour les têtes de pile)

- $2^{\text {ème }}$ position : ferraillage et bétonnage du fût inférieur (pour les embases), du chevêtre (pour les têtes de pile)

- $3^{\text {ème }}$ position : finitions, équipement en passerelles et accès pour le voyage en mer

- $4{ }^{\text {ème }}$ position (pour les embases uniquement) : position de stockage 


\section{XIV ${ }^{\text {èmes }}$ Journées Nationales Génie Côtier - Génie Civil \\ Toulon, 29 juin au $1^{\text {er }}$ juillet 2016}

- $5^{\text {ème }}$ position pour les embases ( ${ }^{\text {ème }}$ pour les têtes de piles) : position de chargement sur la ligne centrale.

Les pièces sont déplacées d'une position à l'autre en utilisant un système de trains de vérins de levage de $250 \mathrm{~T}$ couplés hydrauliquement, et surélevés par rapport à leur rail de glissement par coussins d'air. Chacune des trois lignes est équipée d'une paire de trains de levage (figure 34).
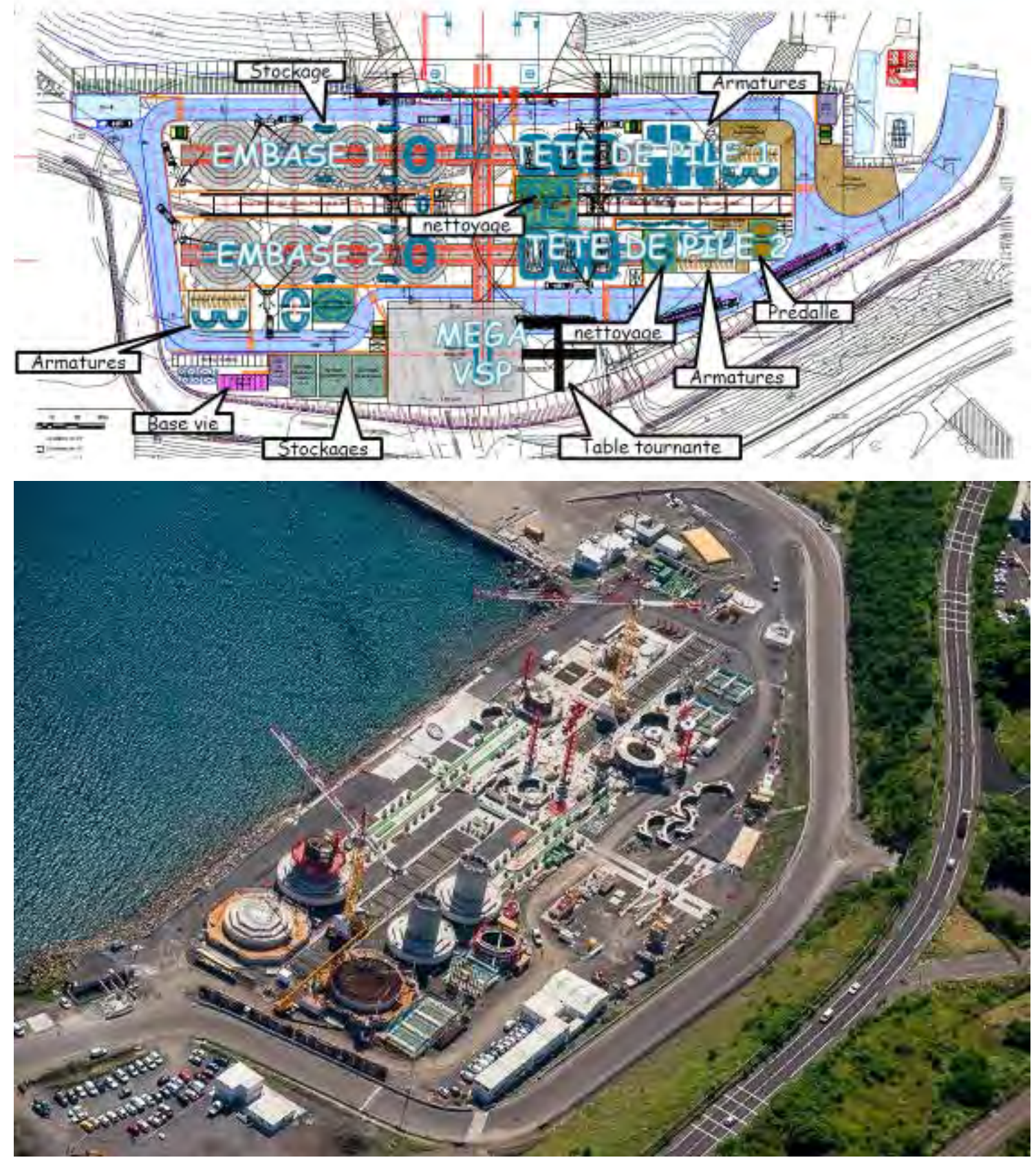

Figure 33. Vue en plan de l'aire de préfabrication des piles. 


\section{Lecture spéciale}

\subsection{Préfabrication des voussoirs}

Les pièces constitutives de l'ensemble du tablier sont préfabriquées sur une aire dédiée, située à un kilomètre environ de la zone portuaire (figures 35 et 36).

Les voussoirs sont préfabriqués à l'aide des outils suivants :

- six cellules coffrantes assurent la production des quatorze types de voussoirs courants (figure 37). La géométrie du tablier à inertie variable implique que la géométrie de ces cellules doit être modifiée pour passer d'un voussoir à l'autre : ceci concerne l'inclinaison du fond de moule, la géométrie du masque et du noyau central (hauteur des âmes), (figure 38).

- deux cellules coffrantes assurent, l'une la production des voussoirs sur pile (VSP) centraux, l'autre la production des VSP latéraux (figures 39 et 40) ;

- une cellule coffrante assure la production des voussoirs sur culée (VSC) ;

- un banc coffrant assure la production des voussoirs des travées de rive.

Ces outils coffrants sont desservis par 4 grues à tour (dont 2 dédiées aux aires de ferraillage) et 2 portiques, l'un de $32 \mathrm{~T}$ destiné à la manutention des éléments des cellules courantes, et l'autre de 350 T dédié à la mise en stock des voussoirs courants.

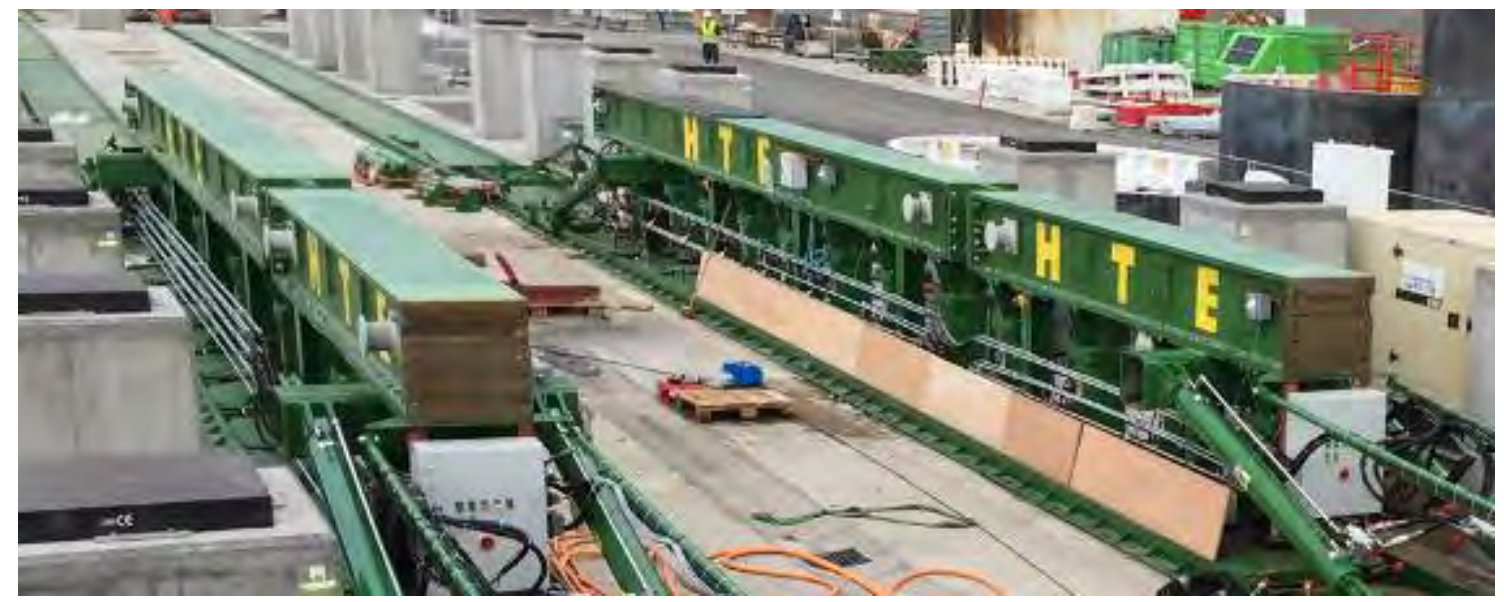

Figure 34. Trains de vérins de levage (système HEBETEC). 


\section{XIVìmes Journées Nationales Génie Côtier - Génie Civil}

Toulon, 29 juin au $1^{\text {er }}$ juillet 2016

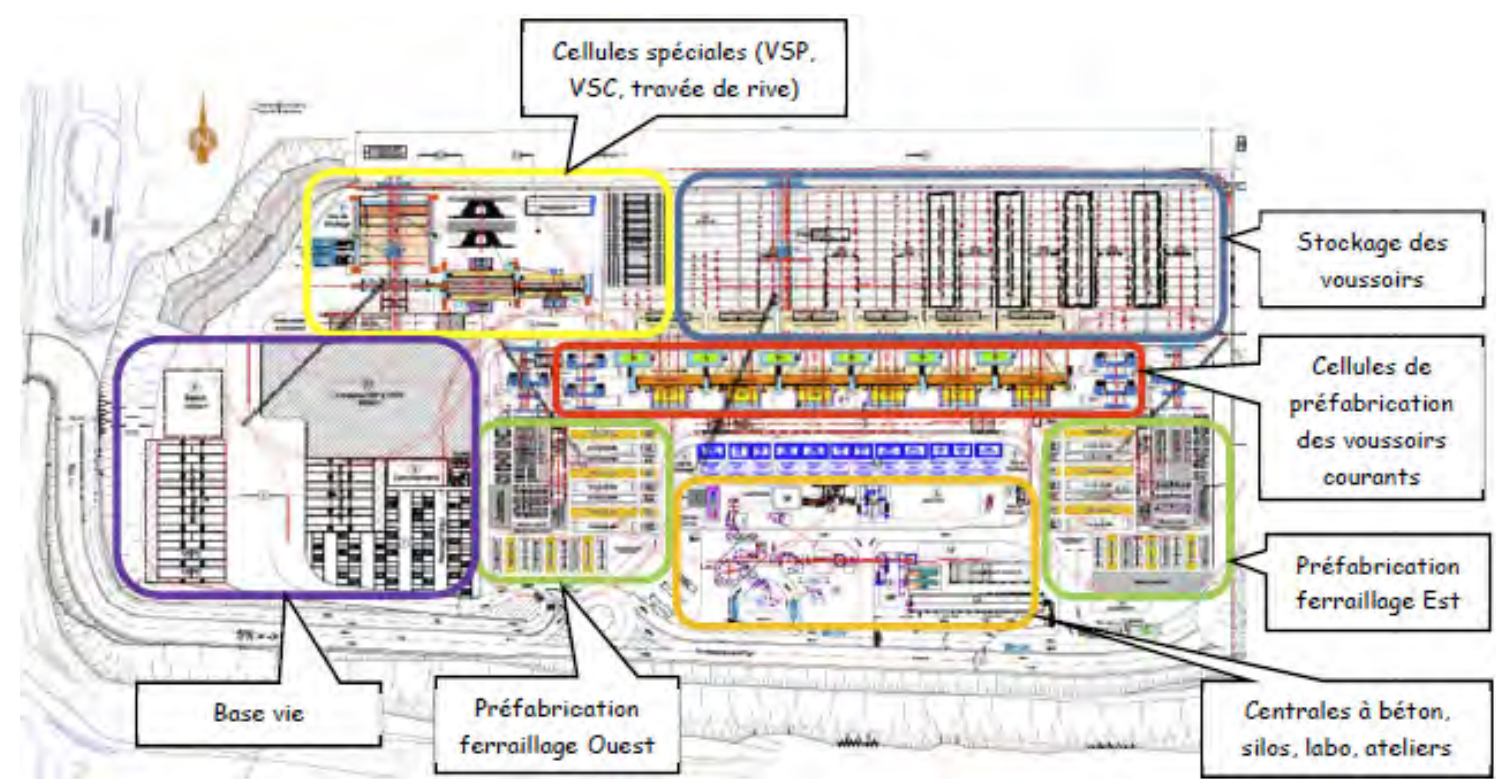

Figure 35. Principe de fonctionnement de l'aire de préfabrication des voussoirs.

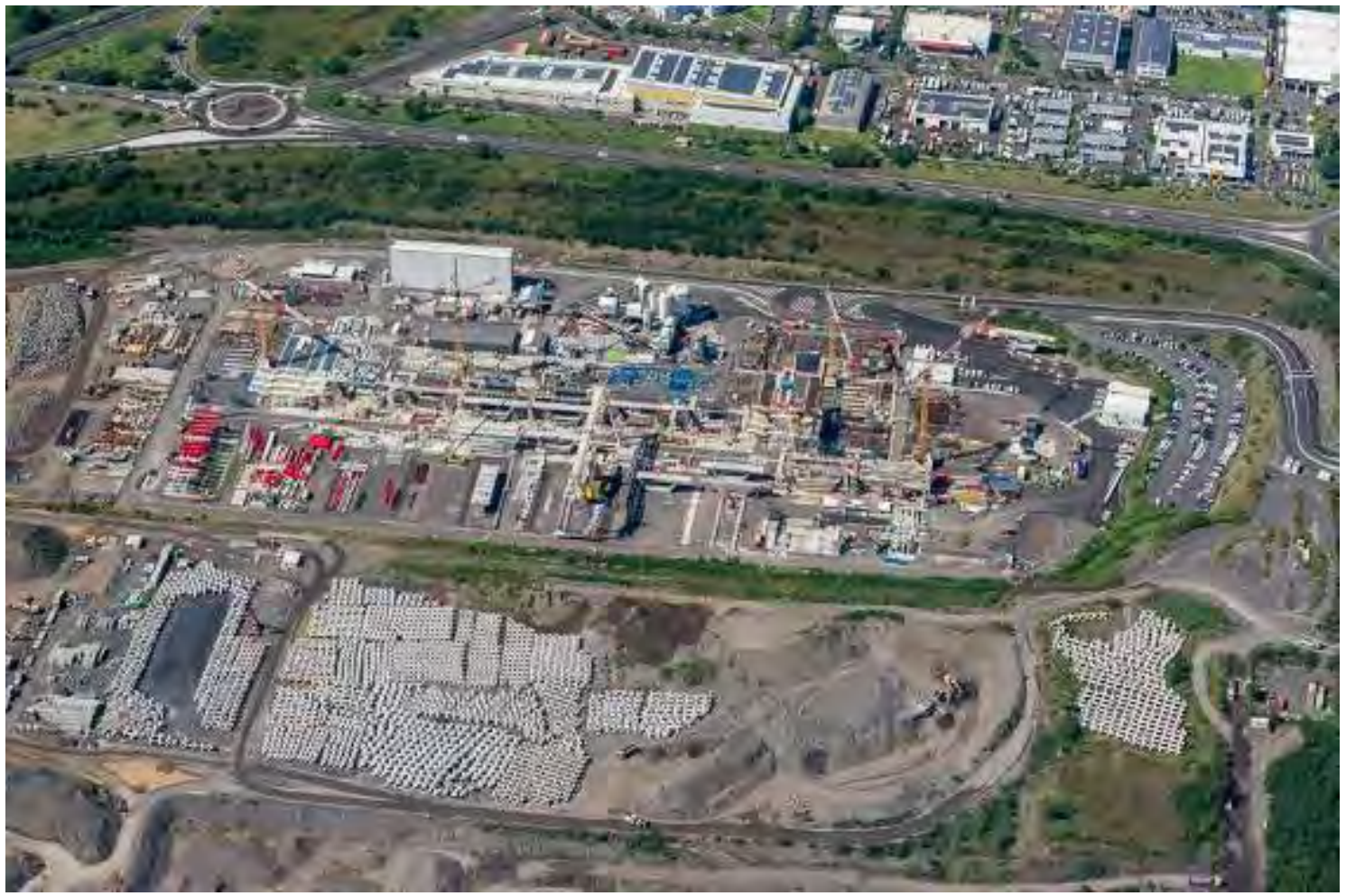

Figure 36. Vue en plan de l'aire de préfabrication des voussoirs. 


\section{Lecture spéciale}

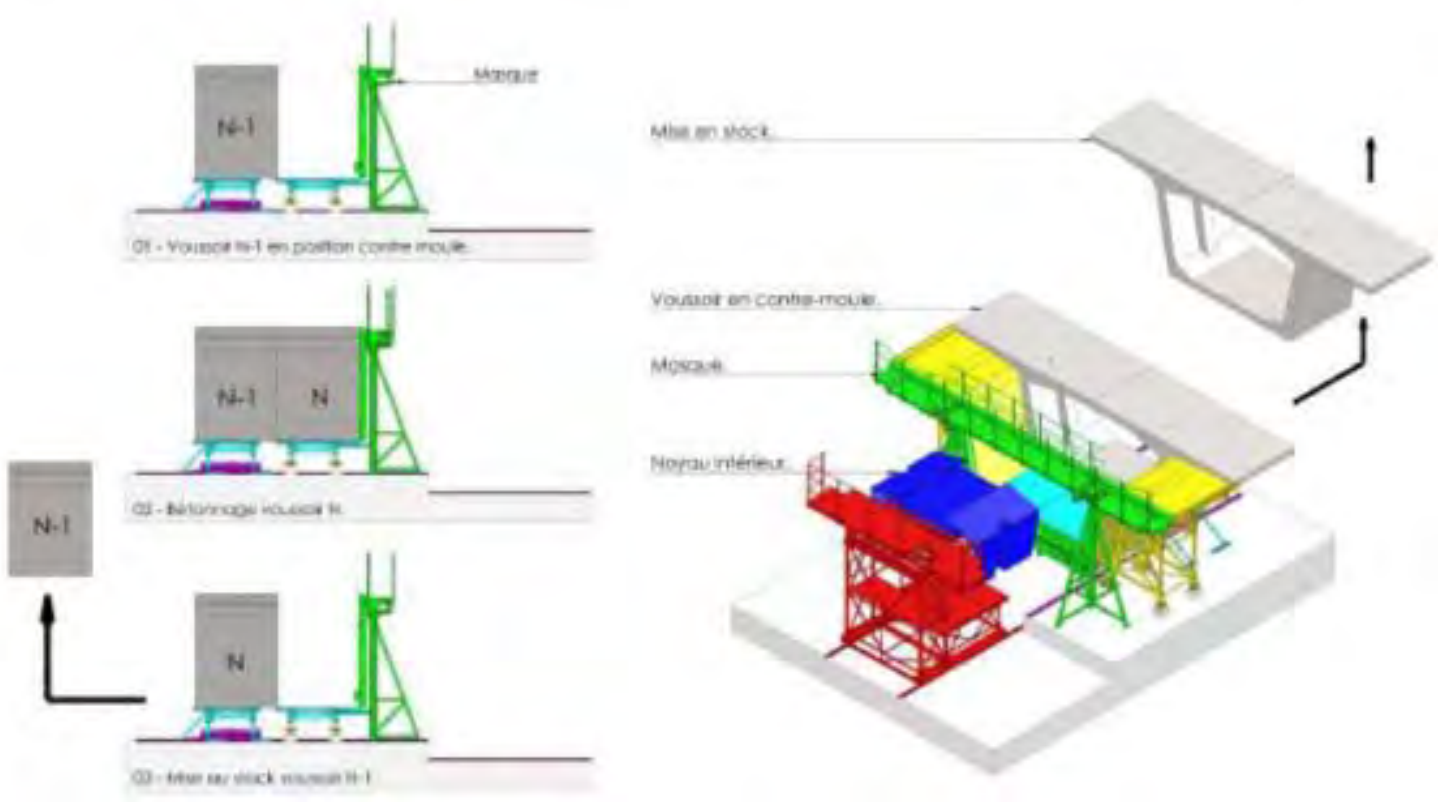

Figure 37. Principe des cellules de voussoirs courants avec conjugaison des voussoirs.

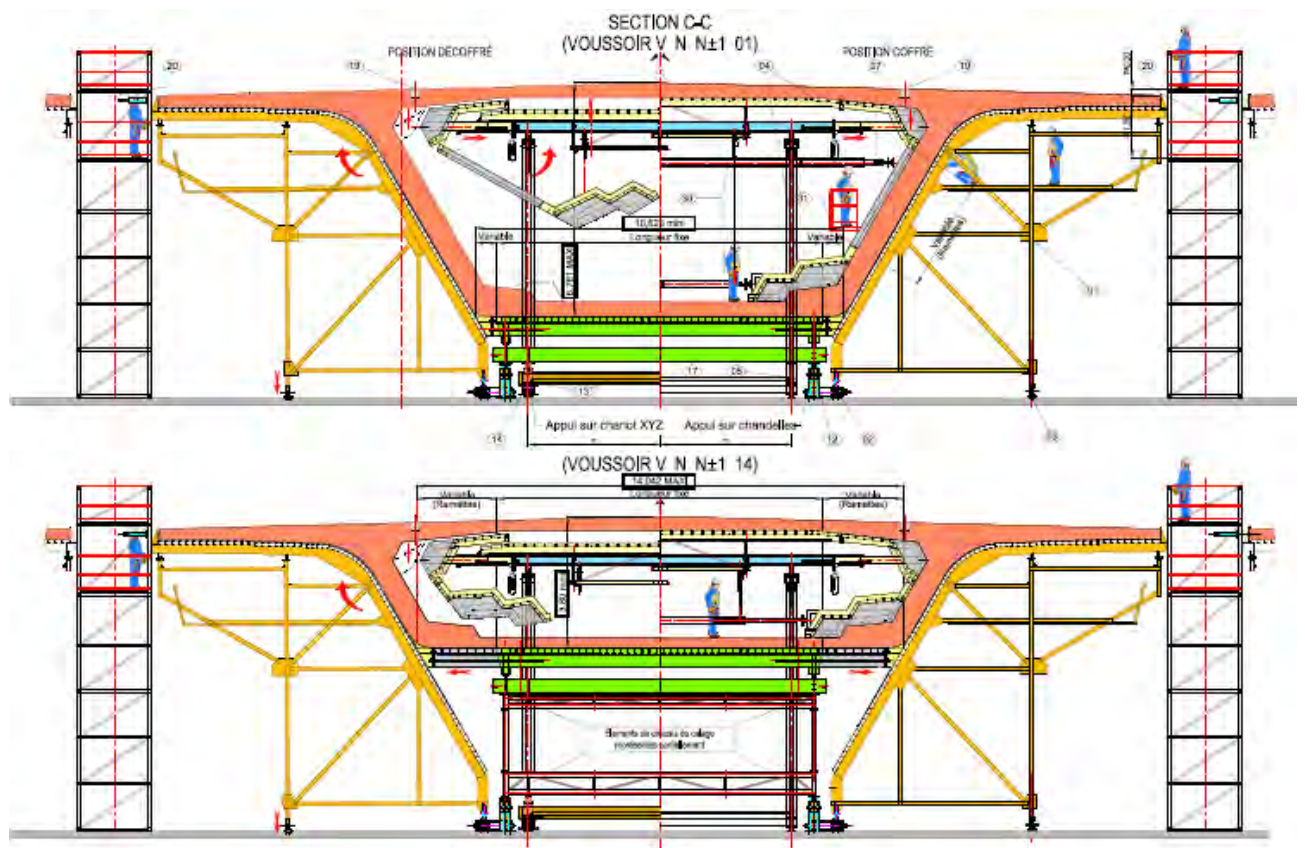

Figure 38. Variations géométriques cellule voussoirs courants. 


\section{XIV èmes Journées Nationales Génie Côtier - Génie Civil \\ Toulon, 29 juin au $1^{\text {er }}$ juillet 2016}

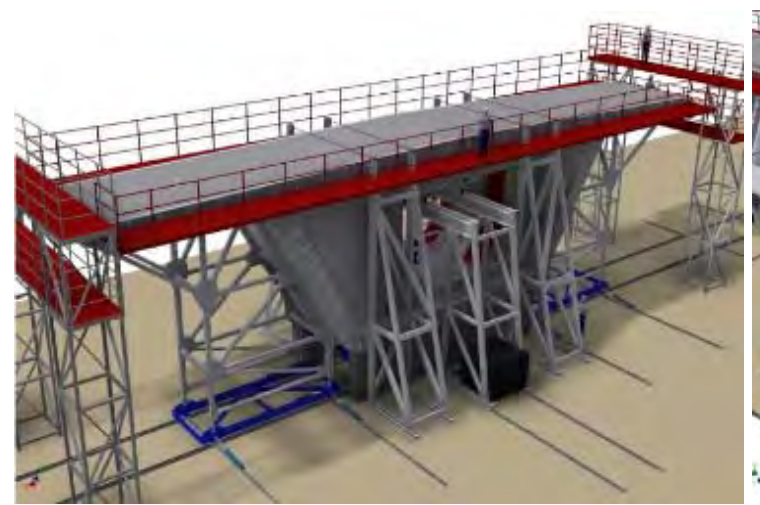

Figure 39. Cellule de bétonnage du VSP central.

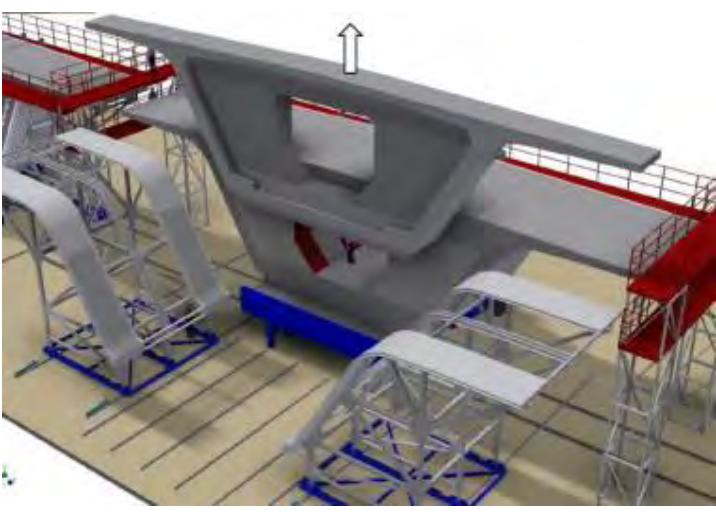

Figure 40. Décoffrage dans cellule VSP latéral (VSP central en contre-moule).

\subsection{Pré-assemblage des méga-VSP}

La notion de méga-VSP résulte d'une optimisation dans l'utilisation de la barge. Celleci est en effet conçue pour transporter des colis de $4800 \mathrm{~T}$, poids maximal d'une embase équipée pour la pose. Or la tête de pile ne pèse que 2400 T environ. Il est donc prévu, comme décrit ci-dessus, d'assembler, et de faire poser par la barge dans le même voyage, les 7 premiers éléments d'un fléau dont le total avoisine également les $2400 \mathrm{~T}$ : le voussoir sur pile (lui-même composé d'un VSP central et deux VSP latéraux) et les deux premières paires de voussoirs courants V1 et V2.

Les éléments préfabriqués sur l'aire des voussoirs seront transportés un par un sur l'aire des piles par le fardier dédié (voir ci-dessous).

Sur l'aire des piles, un système de chariots sur rails permettra d'approcher les pièces et de les assembler par mise en œuvre du brêlage et de la précontrainte afin d'obtenir un "méga-VSP" (MVSP).

Les MVSP seront ensuite transférés sur la barge par le même système de chargement que celui prévu pour les appuis. 


\section{Lecture spéciale}

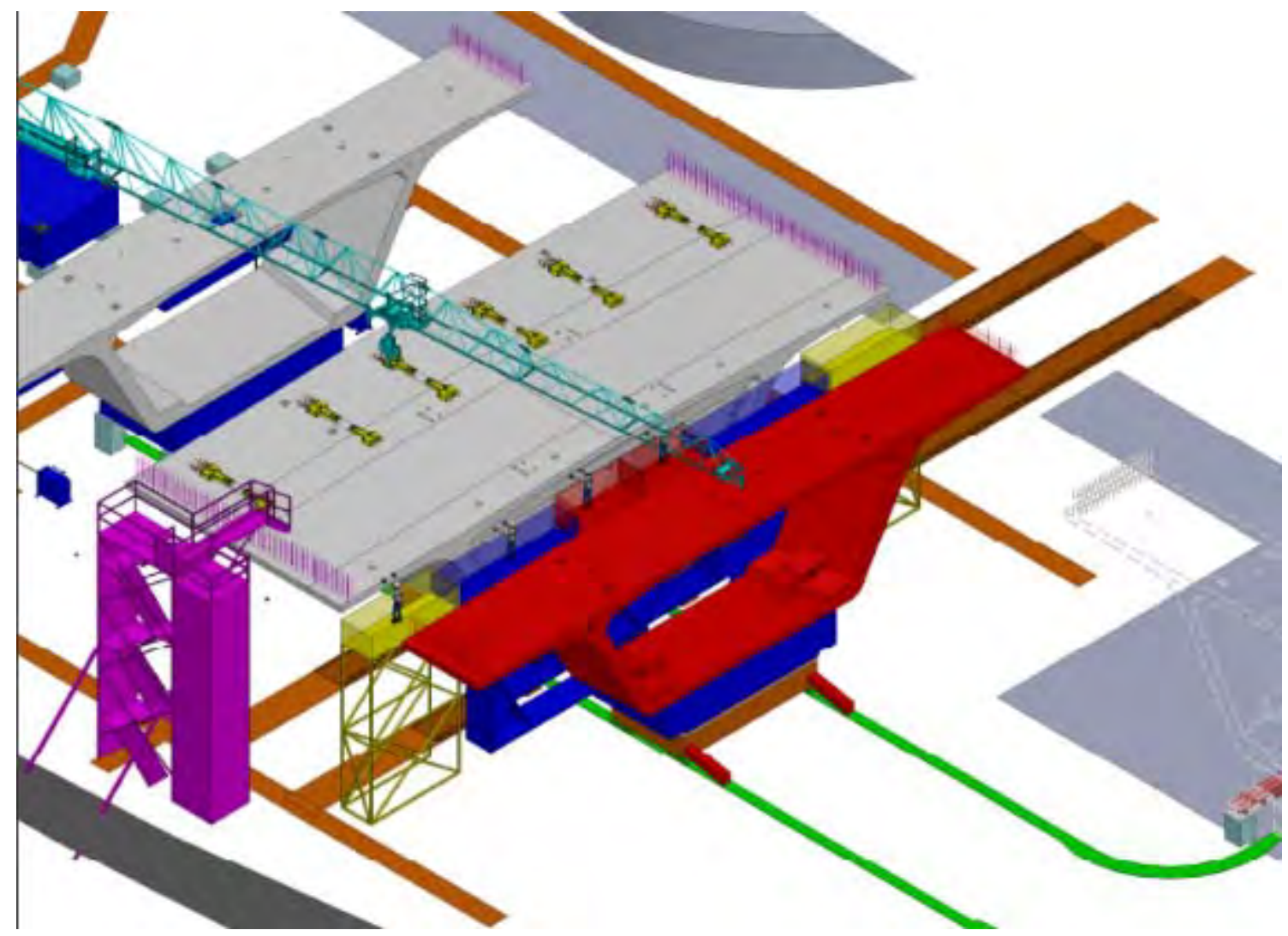

Figure 41. Vue 3D de principe d'assemblage du MVSP.

5.7 Chargement des appuis - barge de transport et de pose

La barge de transport et de pose (Mega Jack-Up Barge - MJUB) "Zourite" a été fabriquée spécialement pour les besoins du projet par les chantiers navals CRIST à Gdynia en Pologne. Les principales caractéristiques de cette barge sont les suivantes :

- Barge autoélévatrice sur 8 jambes de capacité maximale 4000 T chacun ;

- Dimensions importantes : longueur 107 m, largeur 44 m, hauteur 45 m ;

- Desserte par un pont roulant de capacité de levage $4800 \mathrm{~T}$;

- Charges traversant la barge sur toute sa longueur :

- Chargement par l'avant (avec le même système de ripage qu'à terre) ;

- Déchargement par l'arrière (via un "moon pool", avec le pont roulant).

- Centrale à béton embarquée, capacité de production $200 \mathrm{~m}^{3}$ environ. 


\section{XIV vèmes Journées Nationales Génie Côtier - Génie Civil Toulon, 29 juin au $1^{\text {er }}$ juillet 2016}

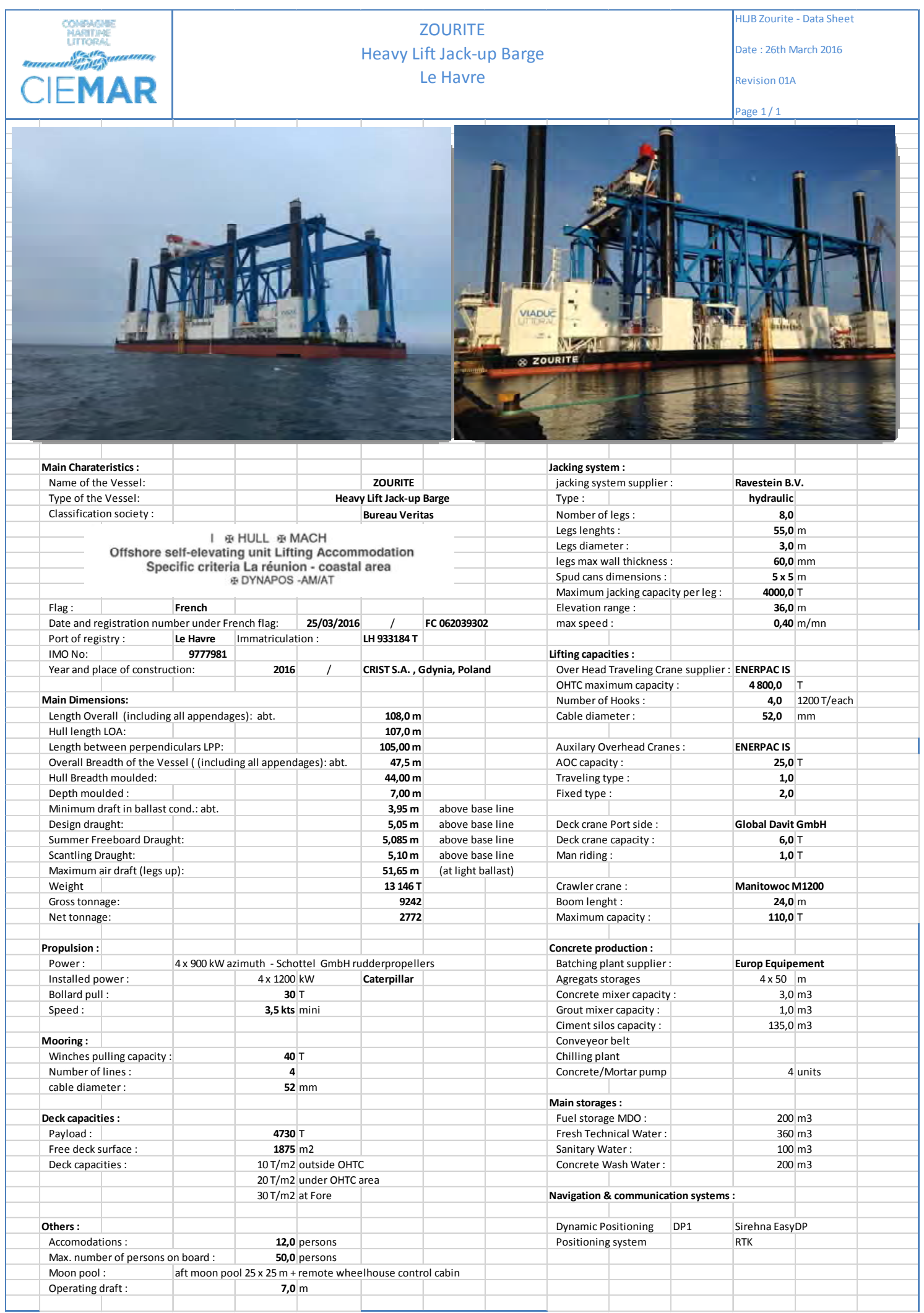

Figure 42. Fiche technique MJUB "Zourite". 


\section{Lecture spéciale}

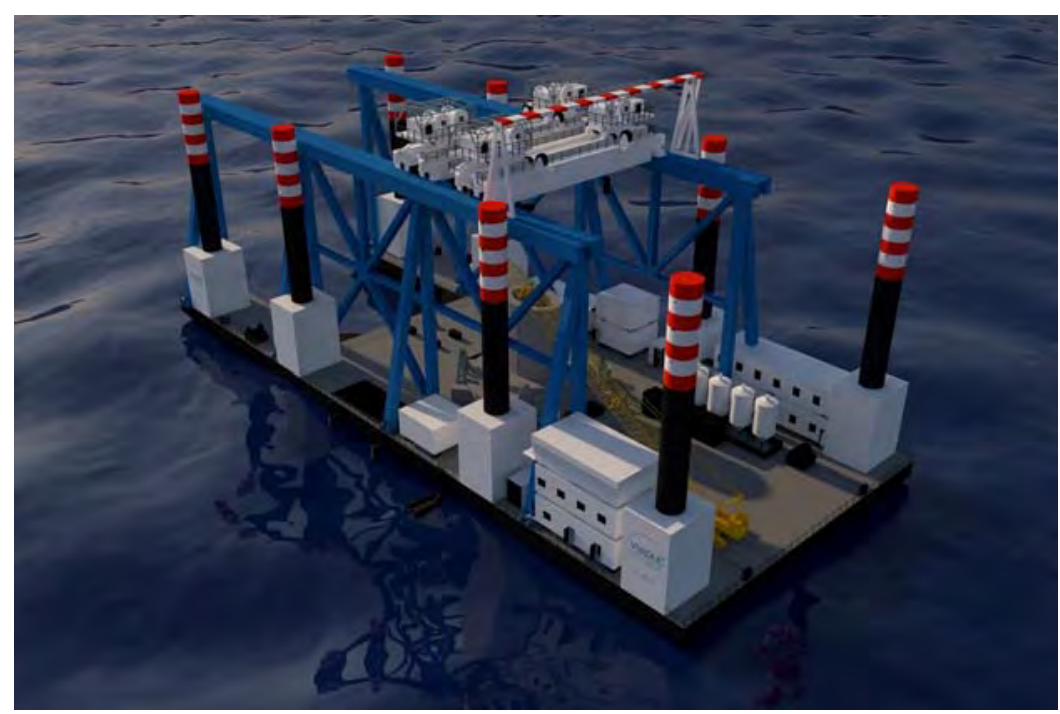

Figure 43. Vue 3D MJUB "Zourite".

Pour le chargement, la barge sera accostée à un quai de longueur $100 \mathrm{~m}$ construit spécialement pour elle, à proximité immédiate de l'aire de préfabrication. Le quai est surélevé (+7,50 NGR) afin de permettre la réalisation de toutes les opérations de chargement en configuration "plateforme". La zone de transfert entre le quai et la barge fait l'objet d'un soin particulier (poutres de transfert appuyées sur une zone renforcée du côté barge, et sur des fondations profondes en arrière du quai du côté terre).

Le chargement des embases et têtes de pile sur la barge depuis le quai s'effectue avec le système de trains de vérins sur coussins d'air employé sur l'aire de préfabrication (voir $\S 5.4)$.

\subsection{Transport des appuis en mer, réglage de la fondation}

Les chargements transportés par "Zourite" seront de deux types :

- Embase seule

- Tête de pile + MVSP (voir la partie "Tablier") + équipement et matériaux nécessaires au clavage de la pile.

Les pièces feront l'objet d'un saisissage avant leur transport. En raison de leur centre de gravité haut placé, les têtes de piles devront être saisies par un système de câbles précontraints pour obtenir les tensions nécessaires.

La barge est pourvue de 4 propulseurs de $900 \mathrm{~kW}$ et réalisera le transport sur site de manière autonome. Le trajet à réaliser varie de 6 à $11 \mathrm{~km}$ suivant les appuis.

Peu avant le premier voyage, la couche d'assise aura fait l'objet d'un réglage au dipper. Ce réglage se fait avec une précision de $\pm 20 \mathrm{~cm}$, raisonnable compte tenu des difficultés liées au travail en mer ouverte. 


\section{XIV èmes Journées Nationales Génie Côtier - Génie Civil \\ Toulon, 29 juin au $1^{\text {er }}$ juillet 2016}

\subsection{Pose de l'embase}

La barge est pourvue d'un système de positionnement (DP) lui permettant de positionner son "moon pool" arrière à la verticale de la fondation. Elle se remettra sur ses jambes pour la pose (travail en position plateforme).

L'embase sera accrochée, via un système de mains de levage spécifiques, au pont roulant de grande capacité. Ce pont roulant transfèrera l'embase horizontalement puis la descendra verticalement au travers du "moon pool" jusqu'à ce que la sous-face de l'embase soit située $20 \mathrm{~cm}$ environ au-dessus du niveau de la couche d'assise.

Dans cette position (embase non posée), l'alignement de l'embase par rapport à l'axe théorique de l'appui sera ajusté par les mouvements du pont roulant assisté par des vérins auxiliaires situés sur les mains de levage, par l'intermédiaire d'un système de positionnement composé d'une centrale inertielle couplée à une centrale d'attitude sur la partie émergée de l'embase et reliée à une antenne GPS.

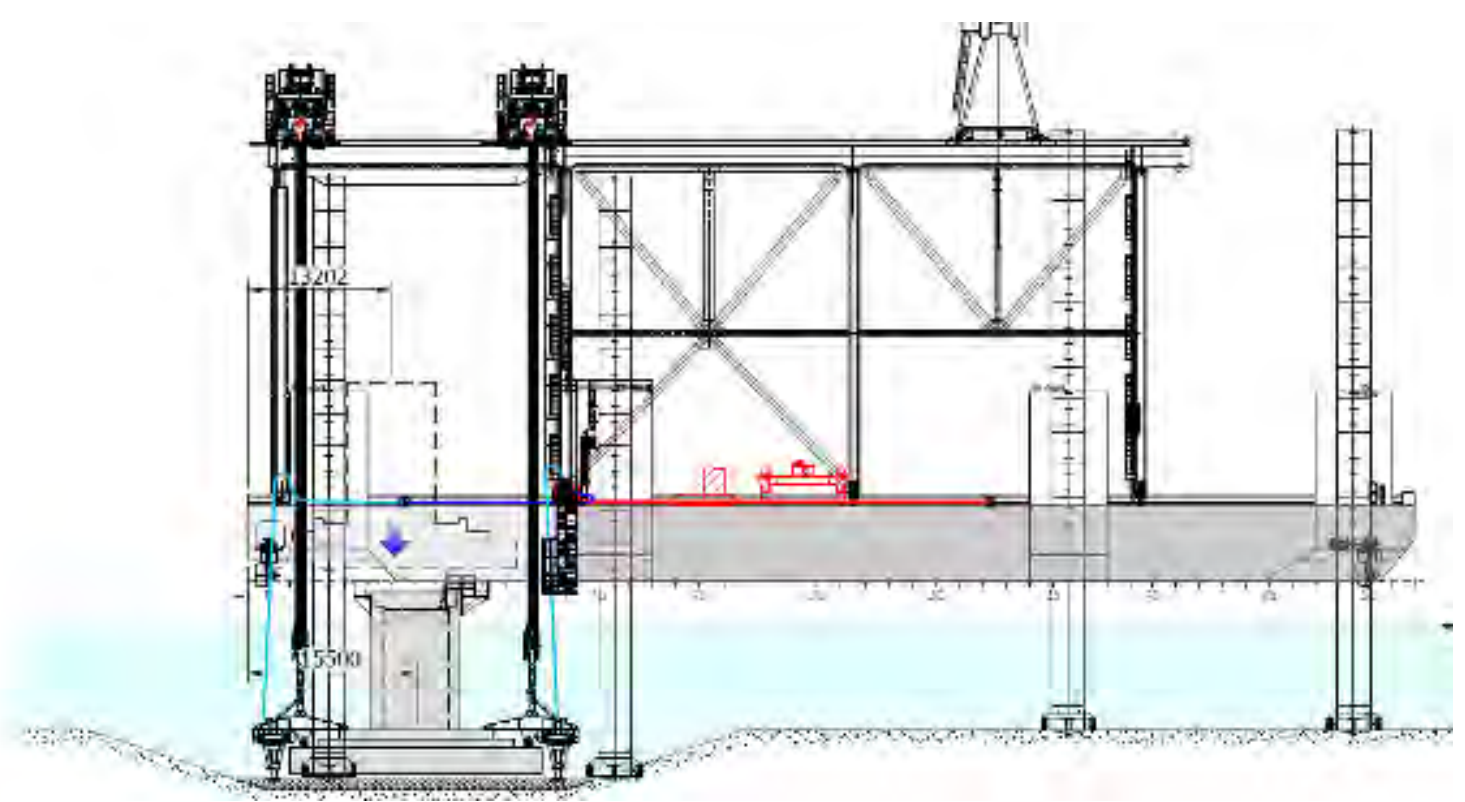

Figure 44. Principe de descente de l'embase.

La différence d'altitude entre la sous-face de l'embase et l'assise sera comblée par remplissage avec un mortier hydraulique de sacs en géotextile, fixés sous la semelle en position repliée avant le chargement. Le remplissage s'effectuera au travers de canalisations insérées dans le béton de l'embase. Le mortier sera fabriqué directement sur la barge par une centrale à béton embarquée. Cette technique permettra de respecter l'interdiction de bétonnage direct en mer, imposée pour des raisons environnementales. Le temps de prise du mortier sera optimisé pour permettre aux mains de levage de relâcher les embases peu de temps après la fin du remplissage (axes de levages commandés à distance par vérins hydrauliques, voir figure 45). La barge sera alors libre de rentrer au port pour son second chargement. 


\section{Lecture spéciale}

\section{VUE EN PLAN EMBASE 20m}
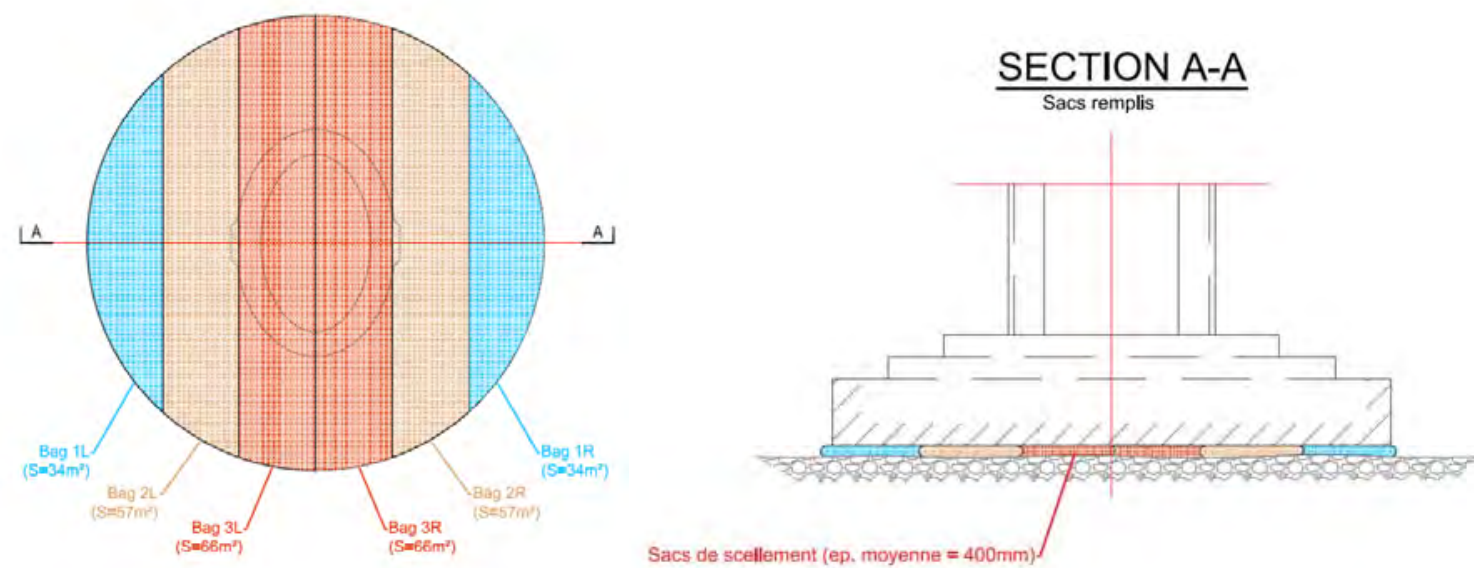

Figure 45. Principe de fonctionnement des sacs de mortier.

\subsection{Pose de la tête de pile et du MVSP}

La tête de pile sera posée en premier par le pont roulant de la barge sur des piliers de calage provisoires aménagés à cet effet dans la partie supérieure du fût de pile amenée avec l'embase.

Le MVSP sera ensuite posé sur la tête de pile par le pont roulant de la barge, sur des cales provisoires.

\subsection{Réglage et clavage de la tête de pile}

La zone de clavage de la tête de pile est située dans les 1,50 m supérieurs du fût de l'embase (figure 46). Elle comprend :

- Des niches recevant les vérins destinés à la dépose et au réglage de la tête de pile ;

- Des piliers pour le calage provisoire de la tête de pile ;

- Des zones de clavage permettant la connexion structurelle entre les deux parties du fût.

Une fois le MVSP posé sur la pile calée, le réglage précis de la position de la tête de pile par rapport à l'embase sera effectué à l'aide des vérins. Ce réglage permettra de rattraper jusqu'à $40 \mathrm{~mm}$ en vertical et $0,2^{\circ}$ en inclinaison.

Une fois le réglage effectué, la charge sera transférée sur les piliers de calage après réalisation d'un matage au mortier.

Les connexions structurelles entre le haut et le bas du fût seront ensuite rétablies par la mise en œuvre d'un ferraillage relié à des manchons assurant la continuité des armatures sur toute la hauteur du fût. Les zones ferraillées seront ensuite bétonnées. 


\section{XIV èmes Journées Nationales Génie Côtier - Génie Civil \\ Toulon, 29 juin au $1^{\text {er }}$ juillet 2016}

La dernière opération consistera à refermer la "porte", ouverture aménagée dans la partie inférieure de la tête de pile pour l'accès aux zones de clavage, selon un procédé similaire.

Ces bétonnages (environ $30 \mathrm{~m}^{3}$ ), réalisés depuis la centrale à béton embarquée sur la barge en position surélevée, représenteront la seule partie des appuis coulée in situ.

La barge pourra alors entamer le cycle de pose suivant.

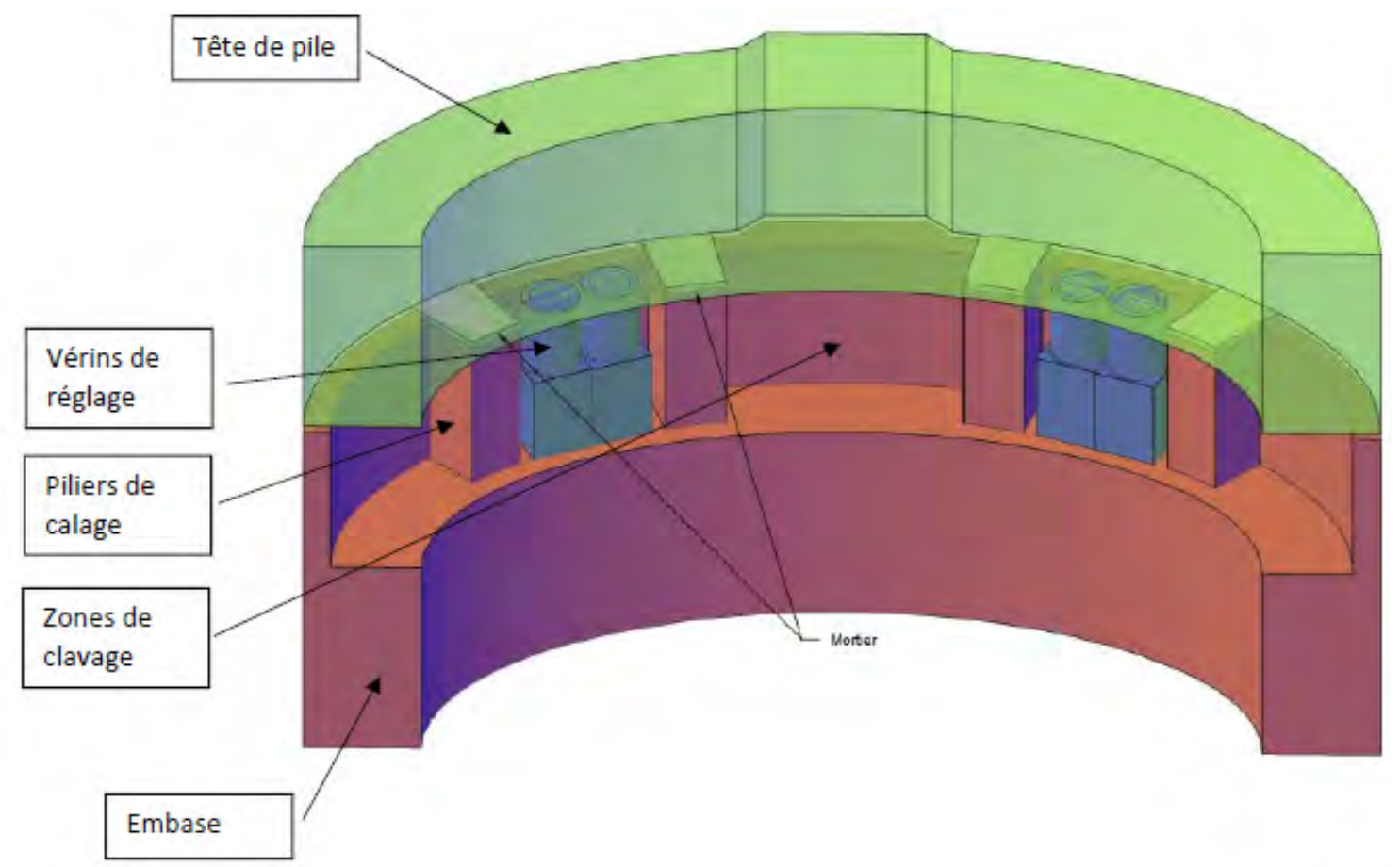

Figure 46. Principe de la zone de clavage.

\subsection{Remblaiement de la fouille}

La fouille créée pour la pose de l'embase est remblayée par le dipper en utilisant les matériaux extraits d'une autre fouille, ou mis en dépôt provisoire.

\subsection{Transport des voussoirs}

Les voussoirs seront transportés depuis l'aire de préfabrication par des fardiers spéciaux capables de transporter ces très lourdes charges tout en respectant les charges maximales à l'essieu des transports exceptionnels, une bonne partie de l'itinéraire se faisant sur des voiries ouvertes à la circulation publique.

Les éléments constitutifs du MVSP (voussoirs sur pile central et latéraux, voussoirs courants V1 et V2), ainsi que les voussoirs sur culée (VSC), emprunteront un corridor reliant les deux aires de préfabrication puis une partie de la route péri-portuaire pour relier l'aire d'assemblage des MVSP. Le colis le plus lourd est le VSP central (600T), soit un convoi de 700T. 


\section{Lecture spéciale}

Les autres voussoirs (voussoirs courants V3 à V14, travées de rive) rallieront la RN1 depuis la route périportuaire et seront acheminés jusqu’à la culée C49 (côté Grande Chaloupe). Le poids du voussoir courant le plus lourd est de $300 \mathrm{~T}$ (soit un convoi de $400 \mathrm{~T})$.

L’itinéraire a été aménagé spécifiquement, avec maintien de la circulation sur la RN1 :

- Vérification des ouvrages d'art existants ;

- Renforcement de certains OA (poutrelles métalliques sur appuis);

- Création de pistes et passages sur radier ;

- Modification des portiques de signalisation.

Ces transports exceptionnels s'effectueront de nuit (en moyenne 4 trajets par nuit, 1400 trajets au total) sous fermeture des chaussées concernées.

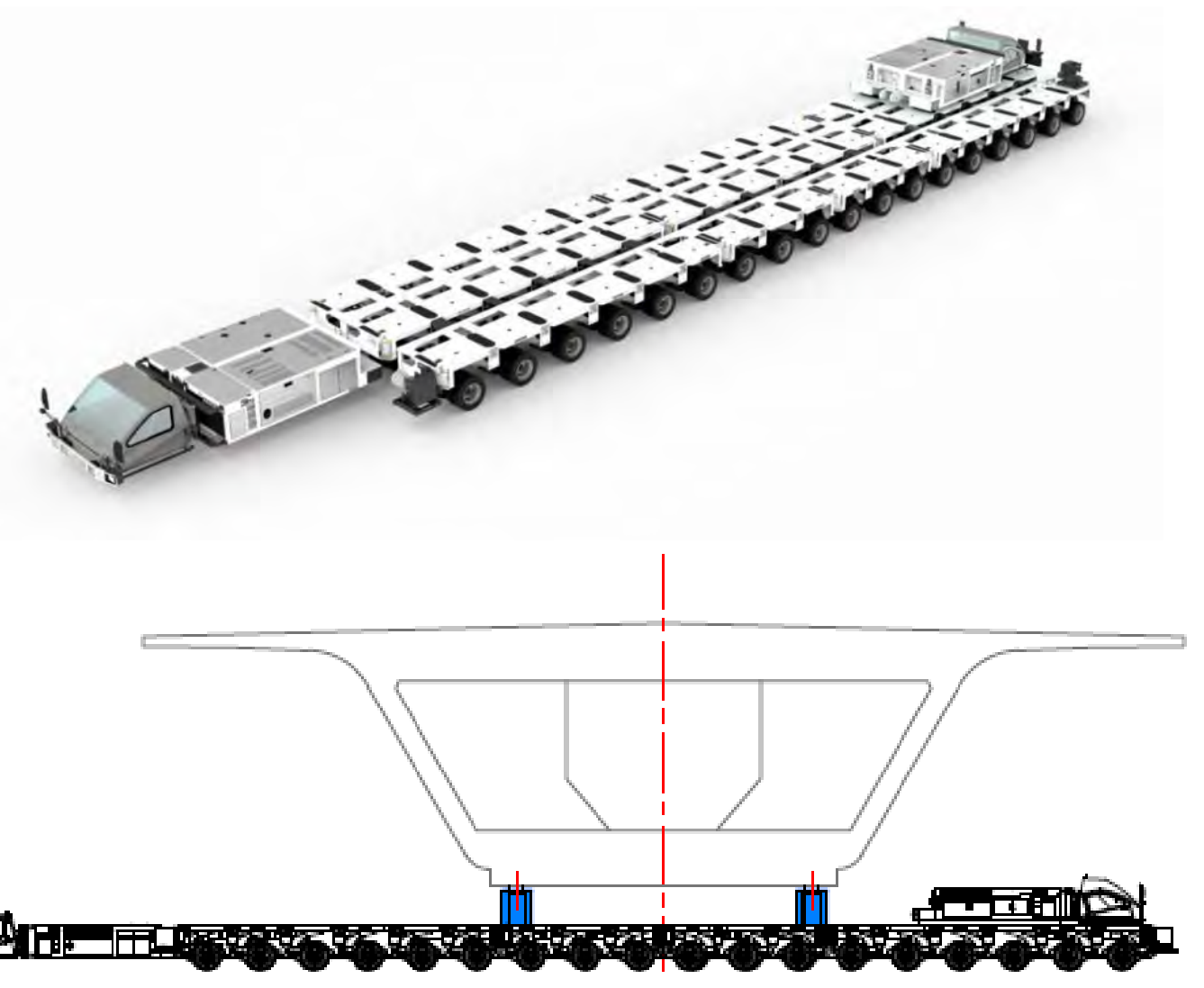

Figure 47. Vue du transporteur et de son chargement.

\subsection{Pose du tablier}

Les voussoirs courants V3 à V14 seront assemblés à partir du MVSP suivant la méthode de construction par encorbellements successifs, à l'aide d'une poutre de lancement pouvant s'appuyer en 3 points :

- Un premier pylône positionné sur la pile du fléau en cours de construction ;

- Un deuxième pylône à l’axe du voussoir sur pile (VSP) du fléau précédent ; 


\section{XIV èmes Journées Nationales Génie Côtier - Génie Civil \\ Toulon, 29 juin au $1^{\text {er }}$ juillet 2016}

- Une béquille positionnée sur le MVSP de la pile située en aval du fléau en cours de construction.

Les voussoirs seront chargés directement par le lanceur depuis les fardiers.

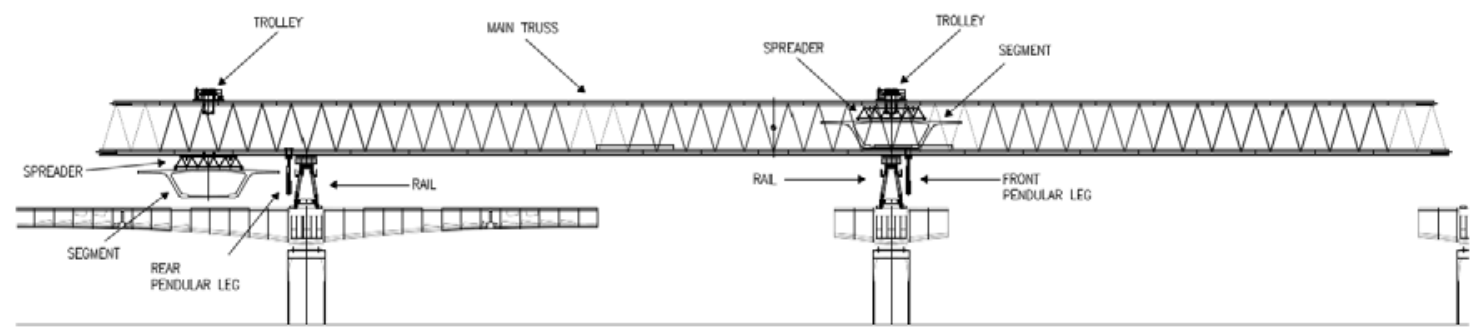

Figure 48. Principe du lanceur.

Caractéristiques du lanceur :

- Longueur : $280 \mathrm{~m}$

- Largeur : $24 \mathrm{~m}$

- 2 poutres de $12 \mathrm{~m}$ de hauteur situées $12 \mathrm{~m}$ au-dessus du tablier

- 2 ponts roulants d'une capacité de levage de $300 \mathrm{~T}$

- Pose par encorbellement des fléaux courants (42 fléaux de $2 \times 12$ voussoirs)

- Pose par suspension des travées de rive ( $2 \times 7$ travées de rive de 5 voussoirs)

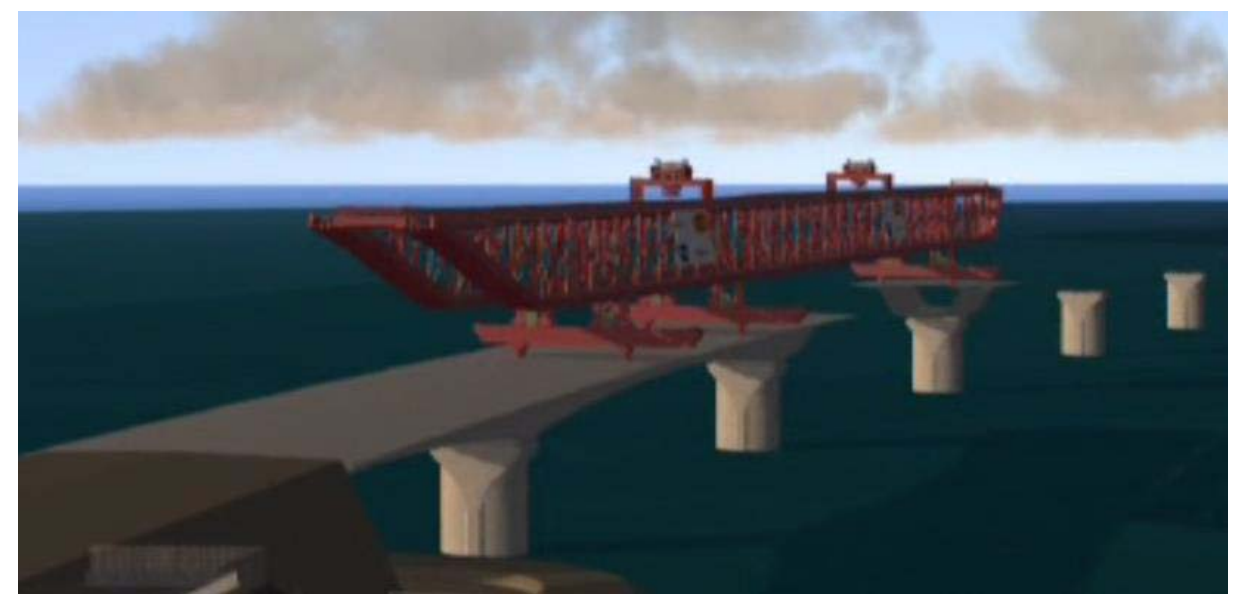

Figure 49. Vue 3D du lanceur en phase de construction

\subsection{Equipements}

Le tablier reçoit les équipements suivants :

- Corniches-caniveaux préfabriquées de grande dimension assurant la collecte des eaux de pluie ;

- Barrières de sécurité type BN1 ;

- Complexe d'étanchéité et sa couche de protection ;

- Chemins de câbles à l'intérieur des voussoirs ;

- Joints de chaussée. 


\section{Lecture spéciale}

\subsection{Tapis anti-affouillement}

Les méthodes de réalisation des tapis anti-affouillement sont en cours de validation.

\section{Conclusion}

Le viaduc en mer de $5400 \mathrm{~m}$ de la Nouvelle Route du Littoral présente des caractéristiques exceptionnelles pour un ouvrage d'art :

- de par ses dimensions intrinsèques ;

- de par son caractère d'ouvrage maritime ;

- de par les conditions de mer rencontrées tant en phase construction qu'en service ;

- de par les contraintes environnementales à prendre en compte.

Pour la réalisation de cet ouvrage, le concepteur EGIS et le Groupement d'entreprises VINCI Construction Grands Projets, Dodin Campenon Bernard, Bouygues Travaux Publics et Demathieu Bard Construction, ont dû mettre en œuvre bon nombre de solutions innovantes ou originales, tant en conception qu'en méthodes d'exécution, visant à limiter la quantité de travaux réalisés en mer et à réduire les risques associés à ces travaux, solutions parmi lesquelles on peut citer :

- Un tablier de dimensions exceptionnelles permettant de limiter le nombre d'appuis à construire en mer ;

- Le passage en fondations superficielles ;

- La préfabrication des appuis du viaduc à terre et leur pose par une barge dédiée ;

- Le recours à cette même barge pour poser la première partie de chaque fléau ;

- La protection autour de chaque pile par des tapis anti-affouillement en béton ;

- Le développement d'outils et de méthodes adaptés à la fabrication, au stockage, à la manutention et à la mise en œuvre de pièces en béton de très grande taille, dans les meilleures conditions de sécurité.

Aujourd'hui, les installations terrestres sont terminées et la préfabrication des piles et des voussoirs est bien entamée. Les matériels maritimes ont été livrés à la Réunion et les travaux de mise en œuvre des éléments préfabriqués vont bientôt commencer. Nous sommes convaincus que le soin apporté aux études et à la préparation des travaux permettront d'aborder au mieux cette phase décisive.

\section{Liste de références bibliographiques}

DUCLOS T., DJESSAS B., CHEBBI F., LEONARD R. (2016). Les viaducs de la Nouvelle Route du Littoral. Article pour le document AFGC "La technique et le savoirfaire français", Congrès IABSE de Stockholm, septembre 2016. 